\title{
Results of a Neutronic Simulation of HTR-Proteus Core 4.2 Using PEBBED and Other INL Reactor Physics Tools: FY-09 Report
}

Hans D. Gougar

September 2009
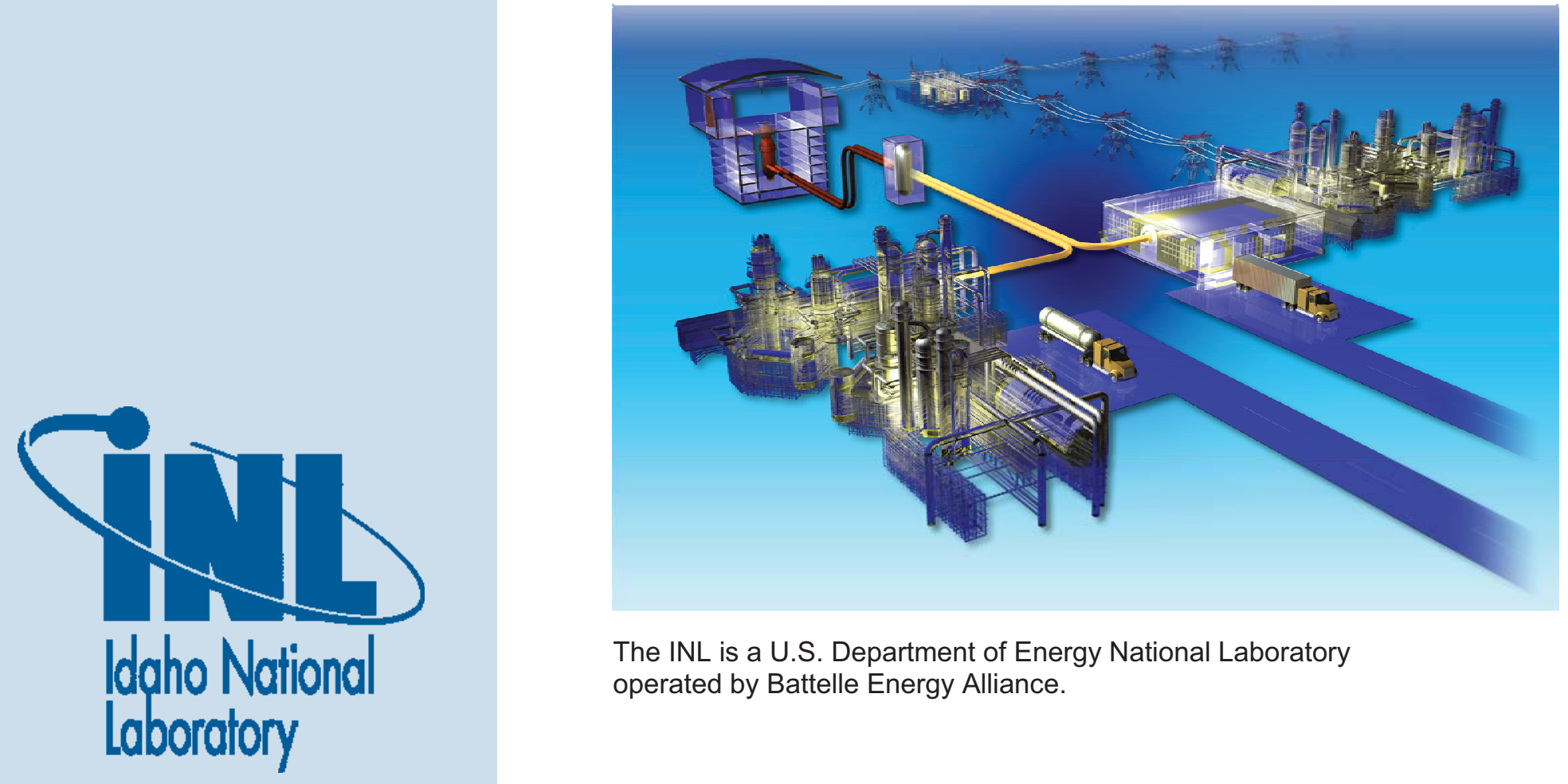

The INL is a U.S. Department of Energy National Laboratory operated by Battelle Energy Alliance. 


\section{DISCLAIMER}

This information was prepared as an account of work sponsored by an agency of the U.S. Government. Neither the U.S. Government nor any agency thereof, nor any of their employees, makes any warranty, expressed or implied, or assumes any legal liability or responsibility for the accuracy, completeness, or usefulness, of any information, apparatus, product, or process disclosed, or represents that its use would not infringe privately owned rights. References herein to any specific commercial product, process, or service by trade name, trade mark, manufacturer, or otherwise, does not necessarily constitute or imply its endorsement, recommendation, or favoring by the U.S. Government or any agency thereof. The views and opinions of authors expressed herein do not necessarily state or reflect those of the U.S. Government or any agency thereof. 


\title{
Results of a Neutronic Simulation of HTR-Proteus Core 4.2 Using PEBBED and Other INL Reactor Physics Tools: FY-09 Report
}

\author{
Hans D. Gougar
}

September 2009

Idaho National Laboratory Next Generation Nuclear Plant Project Idaho Falls, Idaho 83415

Prepared for the

U.S. Department of Energy

Office of Nuclear Energy

Under DOE Idaho Operations Office

Contract DE-AC07-05ID14517 

Next Generation Nuclear Plant Project

\section{Results of a Neutronic Simulation of HTR-Proteus Core 4.2 Using PEBBED and Other INL Reactor Physics Tools: FY-09 Report}

\section{INL/EXT-09-16620}

September 2009

Approved by:

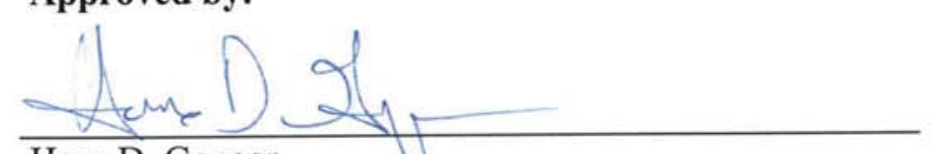

Hans D. Gougar

VHTR TDO Deputy Technical Director

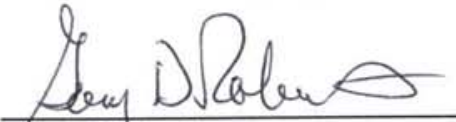

Gary D, Roberts

VHTR TDO Quality Assurance Lead

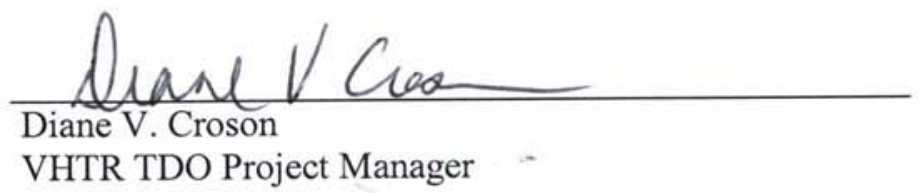

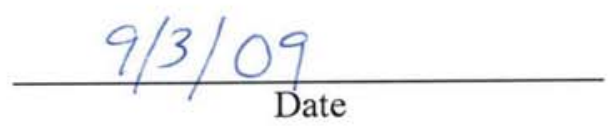
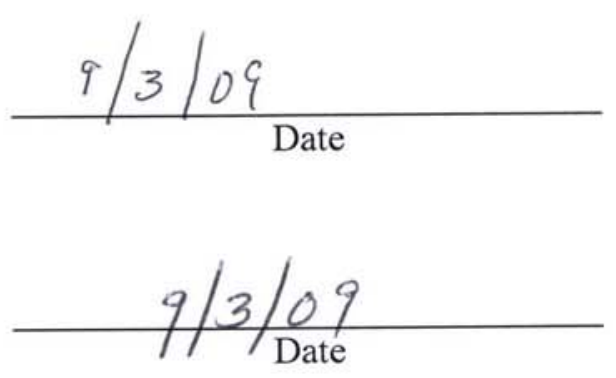



\begin{abstract}
The Idaho National Laboratory's deterministic neutronics analysis codes and methods were applied to the computation of the core multiplication factor of the HTR-Proteus pebble bed reactor critical facility. A combination of unit cell calculations (COMBINE-PEBDAN), 1-D discrete ordinates transport (SCAMP), and nodal diffusion calculations (PEBBED) were employed to yield $k_{\text {eff }}$ and flux profiles. Preliminary results indicate that these tools, as currently configured and used, do not yield satisfactory estimates of $k_{\text {eff. }}$ If control rods are not modeled, these methods can deliver much better agreement with experimental core eigenvalues, which suggests that development efforts should focus on modeling control rod and other absorber regions. Under some assumptions and in 1-D subcore analyses, diffusion theory agrees well with transport. This suggests that developments in specific areas can produce a viable core simulation approach. Some corrections have been identified and can be further developed, specifically: treatment of the upper void region, treatment of inter-pebble streaming, and explicit (multiscale) transport modeling of TRISO fuel particles as a first step in cross section generation. Until corrections are made that yield better agreement with experiments, conclusions from core design and burnup analyses should be regarded as qualitative and not benchmark quality.
\end{abstract}




\section{CONTENTS}

ABSTRACT

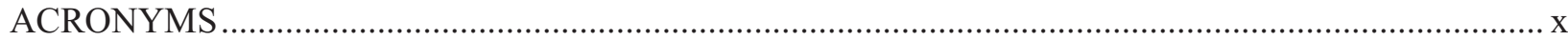

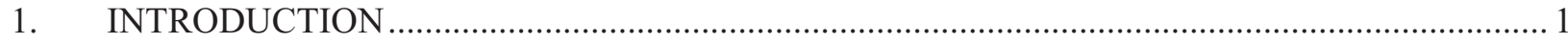

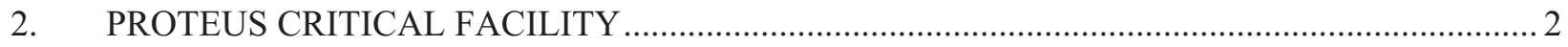

2.1 History and Basic Core Configuration......................................................................... 2

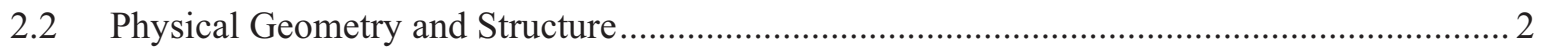

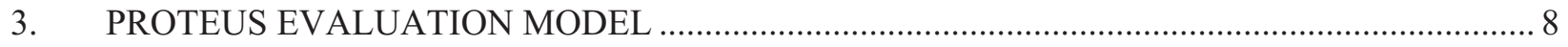

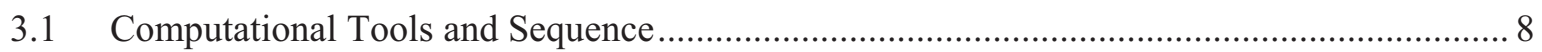

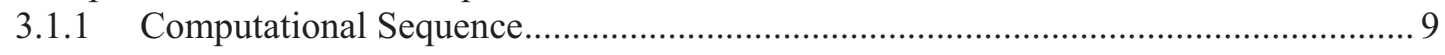

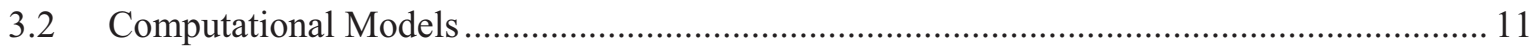

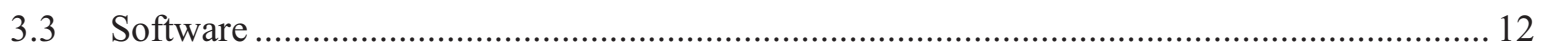

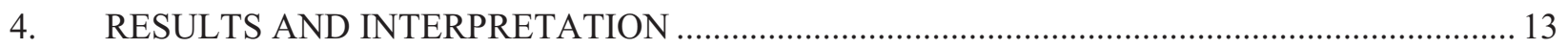

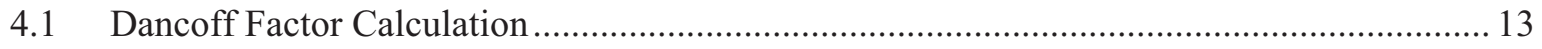

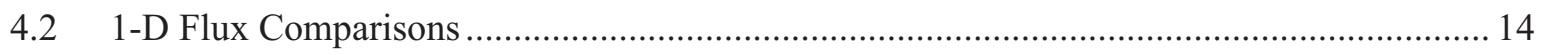

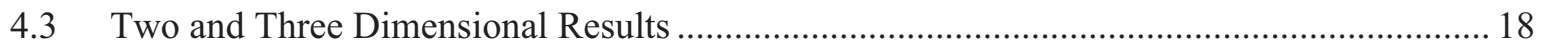

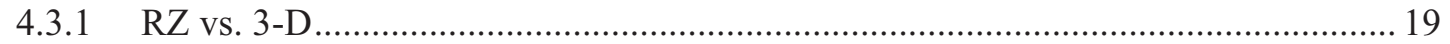

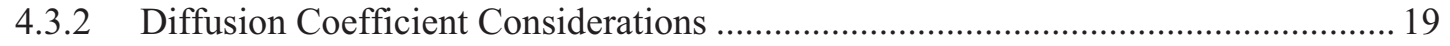

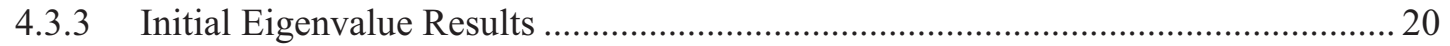

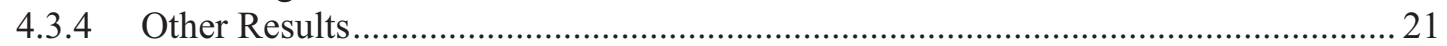

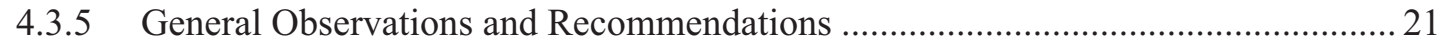

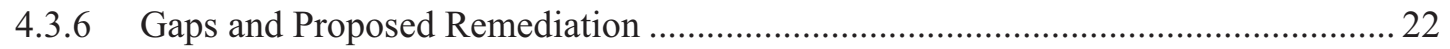

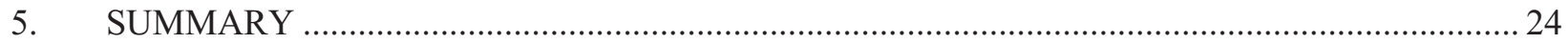

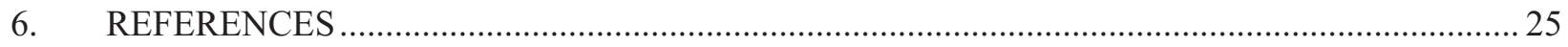

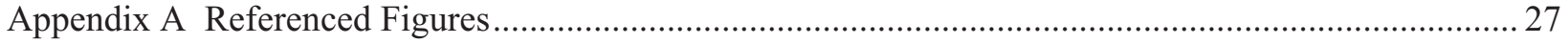

\section{FIGURES}

Figure 1. Cutaway view of Proteus with core, inner, and outer reflectors............................................... 2

Figure 2. Top view of a PROTEUS deterministic core. .................................................................... 3

Figure 3. Schematic side view of the HTR-Proteus facility (dimensions in mm), taken from Reference 7 .......

Figure 4. Cross section through core region showing borings in radial reflector and locations of

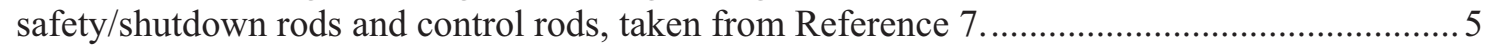

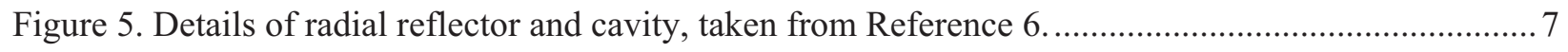

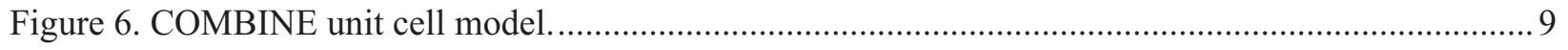

Figure 7. Computational algorithm for the deterministic simulation sequence. ….................................... 10 
Figure 8. Nodalization of the PEBBED RZ core model. ................................................................... 11

Figure 9. Radial variation in pebble packing fraction as computed by PEBDAN .................................... 13

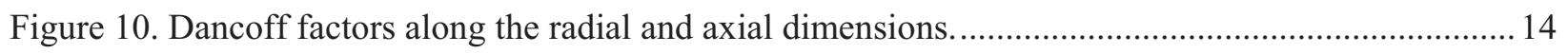

Figure 11. Normalized fast $(>2.38 \mathrm{eV})$ flux profile in radial direction................................................ 15

Figure 12. Normalized thermal $(<2.38 \mathrm{eV})$ flux profile in radial direction. .......................................... 16

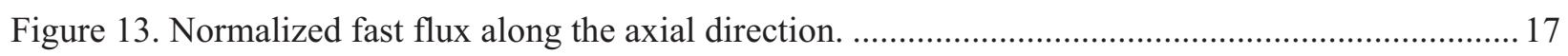

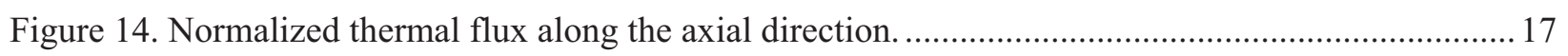

Figure 15. Axially averaged radial power profile: varying vs. constant packing fraction........................ 18

\section{TABLES}

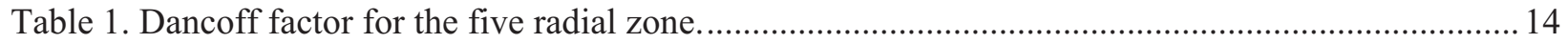

Table 2. Eigenvalues of basic 1D, RZ, and 3D homogeneous, rodded core models..............................20

Table 3. Eigenvalue results from variations in the method..................................................................... 21 


\section{ACRONYMS}

ACR Automatic Control Rod

FD Finite Difference

HPC High Performance Computing

HTR High Temperature Reactor

LWR light water reactor

MCNP Monte Carlo N-Particle

ND Nodal

NGNP Next Generation Nuclear Plant

PBR Pebble Bed Reactor

PBMR pebble bed modular reactor

R\&D research and Development

Sn Discrete Ordinates Scattering of Order $n$

VHTR very high temperature gas-cooled reactor

WCR Withdrawable Control Rod 


\section{Results of a Neutronic Simulation of HTR-Proteus Core 4.2 Using PEBBED and Other INL Reactor Physics Tools: FY-09 Report}

\section{INTRODUCTION}

The Idaho National Laboratory, in support of the Next Generation Nuclear Plant (NGNP) Project, is developing an evaluation model of a candidate pebble bed reactor (PBR) core. This model will be used to investigate critical safety issues associated with the normal and off-normal operation of a pebble bed high temperature reactor. This model will also be used to compute initial and boundary conditions for integral experiments, such as the Oregon State University High Temperature Test Facility, that will be used to investigate specific scenarios and phenomena.

While Monte Carlo neutronics (N)-Particle (MCNP) codes are extremely accurate for some reactor analyses, they are not well-suited to practical PBR core simulations involving fuel depletion or transient behavior. The corewide power and flux profiles that feed into these simulations change with time. Nodal diffusion codes are comparatively fast and efficient and thus remain the most practical option for safety analysis, sensitivity studies, and core design optimization.

The PEBBED code ${ }^{1}$ has been developed at the INL for core design and fuel management optimization of PBR cores. PEBBED simultaneously solves the equations of neutron diffusion, depletion, and pebble motion to yield the equilibrium (asymptotic) burnup state of the PBR. PEBBED requires as input the region-wise few-group cross sections required of diffusion and depletion analysis. These cross sections can be supplied directly or computed online using the optional thermal-hydraulic (THERMIXKONVEK) and spectrum (COMBINE) modules.

PEBBED is a steady state diffusion and burnup code. Transient core behavior resulting from reactivity insertions requires a proper kinetic (time-dependent) diffusion solver. The kinetic complement to PEBBED is the Idaho National Laboratory (INL) code CYNOD. CYNOD models short-term transient behavior such as xenon and rod withdrawal transients, but cannot simulate long-term burnup. Together, these codes can be used to simulate a wide variety of PBR operating scenarios. CYNOD was recently incorporated into the RELAP5 systems analysis code to enable modeling of plantwide phenomena in PBRs. ${ }^{2}$

Neutronic verification of PEBBED has thus far been limited to tests of the standalone diffusion and depletion solvers. The diffusion solver has been verified against solutions to simple core problems for which analytic solutions were computed. ${ }^{3}$ The depletion solver was verified by comparing burnup and specific nuclide concentrations under various conditions against the pebble bed modular reactor (PBMR) code VSOP99. ${ }^{4}$ In all of these cases, cross sections were supplied to PEBBED for subsequent diffusion or depletion analysis.

Validation of a core model requires comparisons to actual physical systems. Low power critical reactors have been designed and operated for neutronic validation. The PROTEUS facility in Switzerland operated from 1992 to 1996 in support of high temperature reactor research programs. ${ }^{5}$ The reconfigurable core was used to validate both prismatic and PBR physics codes. Core \#4 of the campaign was a randomly loaded pebble bed core, and was thus used in this study to validate the INL suite of deterministic PBR physics tools. This report summarizes the results of the initial modeling efforts. 


\section{PROTEUS CRITICAL FACILITY}

\subsection{History and Basic Core Configuration}

Proteus is a zero-power research reactor operated by the Paul Scherrer Institute in Switzerland. The basic geometry is that of a cylindrical graphite annulus with a central cylindrical cavity (see Figure 1). The graphite annulus remains basically the same for all experimental programs, but the contents of the central cavity are changed according to the type of reactor being investigated. Through most of its service history, Proteus has represented lightwater reactors, but from 1992 to 1996, Proteus was configured as a PBR critical facility and consequently designated as HTR-Proteus. During this period, 13 critical configurations were assembled and various reactor physics experiments were conducted.

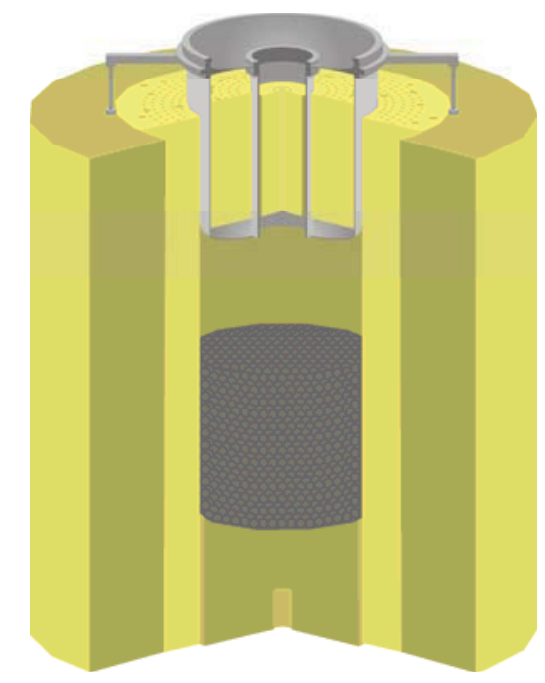

Figure 1. Cutaway view of Proteus with core, inner, and outer reflectors.

These experiments included measurements of criticality, differential and integral control rod and safety rod worths, kinetics, reaction rates, water ingress effects, and small sample reactivity effects.

HTR-Proteus was constructed, and the experimental program was conducted to provide experimental benchmark data for assessment of reactor physics computer codes. Considerable effort was devoted to benchmark calculations as a part of the HTR-Proteus program. References 6 and 7 provide detailed data for use in constructing models for codes to be assessed. Reference 5 is a comprehensive summary of the HTR-Proteus experiments and the associated benchmark program. This document draws freely from these references. Section 2 provides a simple description of the geometry.

\subsection{Physical Geometry and Structure}

The fuel elements in any PBR are spherical "pebbles" roughly the size of billiard balls, composed of a graphite matrix in which thousands of tiny (approximately $1 \mathrm{~mm}$ diameter) coated fuel particles are embedded. In an operating PBR, the pebbles are dropped in from one or more drop points above the core and removed at the bottom, so that the core slowly flows downward, and the pebbles are normally circulated through the core several times (typically about ten) before they are discarded after reaching their burnup limit. During their passage through the core cavity, they acquire a random and continually changing arrangement. It is possible to define a randomly loaded pebble bed for modeling purposes, but 
such a model only represents one of an infinite number of possible arrangements. The probability of a randomly loaded model accurately representing an actual specific randomly loaded experiment is essentially zero.

Thirteen critical configurations were assembled in the HTR-Proteus experimental program. These configurations differed in the arrangement of their cores. In three of the experimental configurations (Cores 4.1, 4.2, and 4.3) the pebbles were randomly loaded into the central cavity. In the remaining 10, the pebbles were arranged manually into lattices. The experimenters used the term "deterministic" to denote these regular cores. These lattices were either hexagonal close-packed or hexagonal point-on-point configurations. The former arrangement is like oranges in a crate as shown in Figure 2. In the latter configuration, the pebbles are in successive layers that form columns without any relative lateral displacement. These deterministic arrangements are considered much more useful for benchmarking reactor physics computer codes. In fact, they have been the focus of benchmarking activities in the NGNP Methods program. ${ }^{8}$ The randomly loaded cores, however, better reflect the designs proposed for commercial reactors, including the PBMR 400. ${ }^{9}$

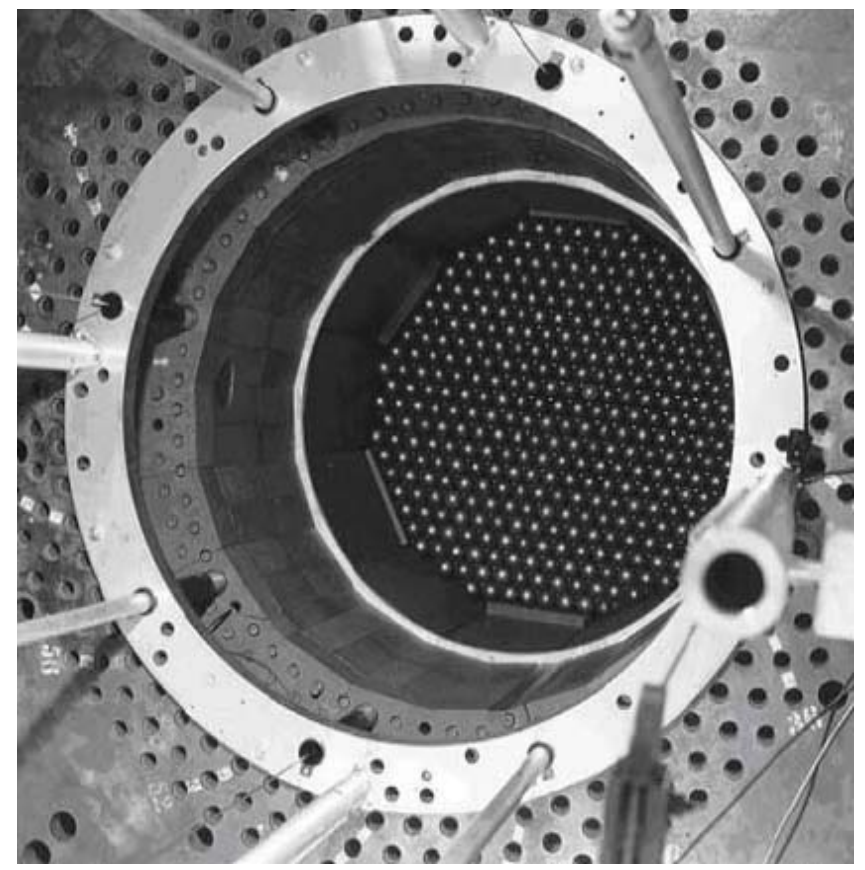

Figure 2. Top view of a PROTEUS deterministic core.

HTR-PROTEUS Core 4 was loaded by dropping pebbles into to the core cavity from a loading tube suspended above the core. This core has not yet been modeled with MCNP, given the difficulty in defining the locations of randomly located pebbles in the MCNP model.

A schematic side view of the HTR-Proteus facility is shown in Figure 3.

The reflector consists of three basic regions, the lower axial reflector, the radial (or side) reflector, and the upper axial reflector. The radial reflector extends from the core cavity radial boundary to the outer radial boundary of the reflector and from the base of the reflector upwards to a height of $3,304 \mathrm{~mm}$. The lower axial reflector is the reflector region below the core cavity and the upper axial reflector is the region above the core cavity. The upper axial reflector is suspended above the core cavity and extends above the top of the radial reflector as shown above. No information has been obtained regarding the number or azimuthal extent of the support structures that suspend the upper axial reflector. 


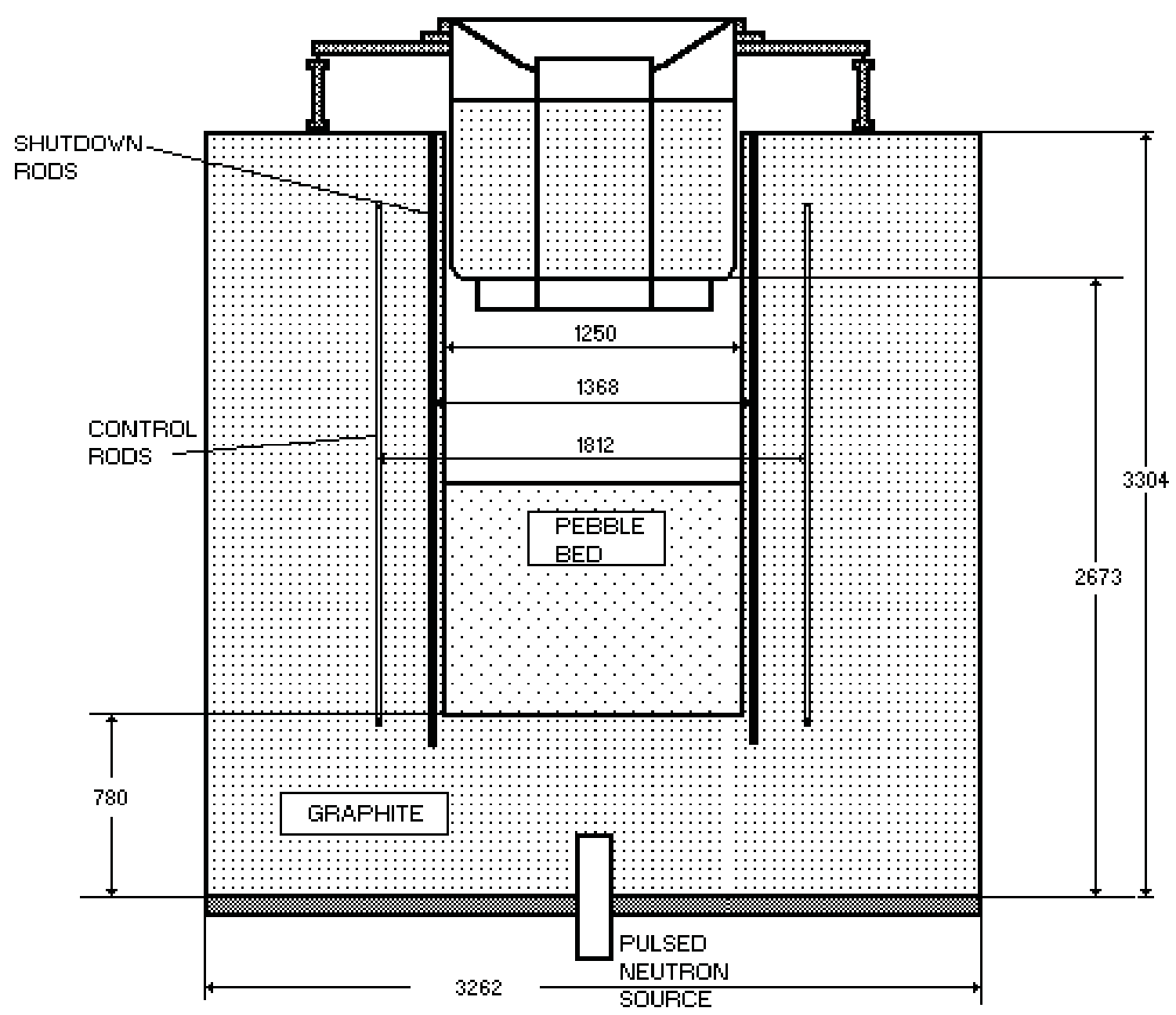

Figure 3. Schematic side view of the HTR-Proteus facility (dimensions in mm), taken from Reference 7.

The upper axial reflector is a complex structure containing graphite, aluminum, and steel. It includes inner and outer aluminum tanks, an aluminum safety ring to prevent the upper axial reflector from falling onto the pebble bed in an accident, and a steel lid, support plate, and flanges.

The lower axial reflector has a boring in the bottom for placement of the pulsed neutron source, which was not modeled in this study. It also contains 160 symmetrically located borings $27.43 \mathrm{~mm}$ in diameter, of which at least 127 (the exact number depends on the core configuration) are filled with graphite rods $26.5 \mathrm{~mm}$ in diameter for the entire height of the lower axial reflector. The remainders of the borings serve as coolant channels, which remain open to the core cavity. These coolant channels, when not filled with graphite, are located at radii of 300,410 , and $515 \mathrm{~mm}$ and angles of 16.875, 50.625, $84.375,118.125,140.625,174.375,208.125,241.875,275.625,309.375$, and 343.125 degrees clockwise from a reference angle (the $+x$-axis shown in Figure 4). The upper axial reflector contains coolant channels located in the same places as the coolant channels in the lower axial reflector, plus an additional one on the core centerline. In the upper axial reflector, these 34 channels are always open.

A graphite structure called the thermal column is $1,200 \mathrm{~mm}$ high by $1,200 \mathrm{~mm}$ wide on one side of the radial reflector, as shown in Figure 4. Its radial depth is about $500 \mathrm{~mm}$. It extends from a level of $984 \mathrm{~mm}$ above the bottom of the radial reflector upwards to a level of $1,120 \mathrm{~mm}$ below the top of the radial reflector. 


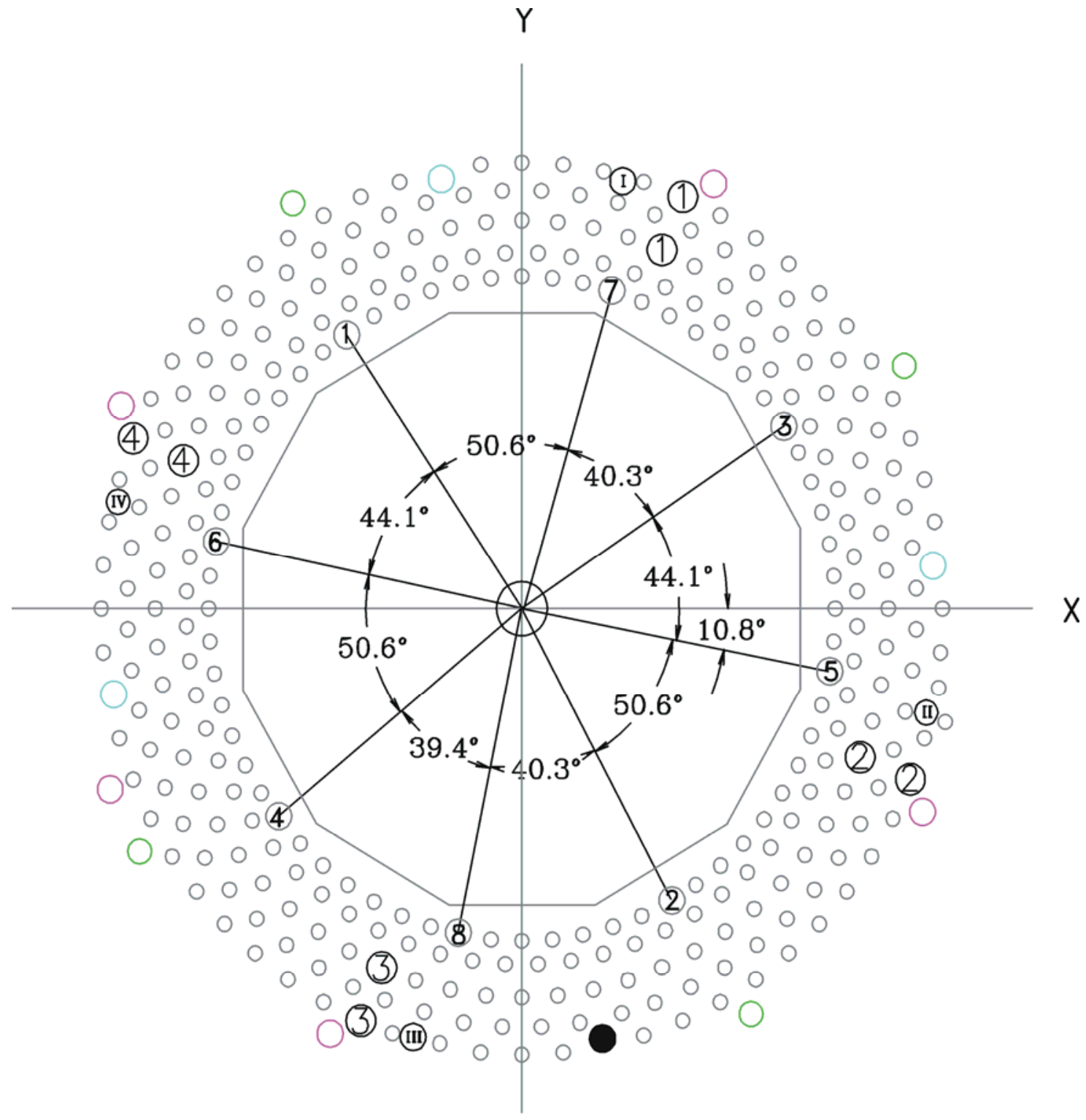

\section{(1)-(4) - control rods (2 possible radial positions)$$
\text { (1)-(8) - safety and shutdown rods }
$$$$
\text { - automatic control rod }
$$$$
\text { (1) - (1) - Zebra control rods }
$$

Figure 4. Cross section through core region showing borings in radial reflector and locations of safety/shutdown rods and control rods, taken from Reference 7.

Finally, the entire reactor system is surrounded by concrete shielding. None of the available references provided any information regarding the thickness of the concrete. For this study, a thickness of 1 meter was assumed. 
Figure 4 also shows a horizontal cross section through the core region of a generic experimental configuration. This figure shows numerous borings in the reflector near the core, some of which are occupied by control elements of various kinds.

The borings in the radial reflector are designated as C-Driver locations. They are arranged in five rings. The first, third, and fifth rings are aligned radially, while the second and fourth rings are shifted azimuthally one-half of the angular spacing between borings in a ring. There are 320 of these borings, which are $27.43 \mathrm{~mm}$ in diameter. More than 300 of them were filled with graphite rods $26.5 \mathrm{~mm}$ in diameter, but some locations were used for control rods and safety/shutdown rods.

The radial outer boundary of the radial reflector is shaped as an irregular 22-sided polygon 3,262 mm across, as shown in Figure 5. The radial inner boundary of the radial reflector is a similar irregular 22 -sided polygon $1,250 \mathrm{~mm}$ across the flats. Note that one of the inner flats, at $62 \mathrm{~mm}$ wide, is smaller than the others at $185.5 \mathrm{~mm}$.

For the hexagonal close-packed cores, additional spacers were placed in alternate layers to fill the gaps created by the horizontal displacement of these layers relative to the adjacent layers. These spacers were not used in the stochastic cores, but wedges were placed around the bottom of the core cavity to simulate a conical discharge region.

The pebbles were loaded via drop tubes while the top reflector was removed. The fuel pebbles each contained just under 5,000 TRISO particles with a heavy metal loading of uranium enriched to $20 \%$ U-235. Pure graphite (moderator) pebbles were also loaded in specified proportion to the fuel pebbles. For Core 4.2, the fuel-to-moderator pebble ratio was 1:1. Core 4.1 was omitted because the nature of the pebble loading mechanism. A single moveable tube provided the pathway for both fuel and moderator pebbles. There were, however, doubts about the randomness of the fuel and moderator pebble distribution. For Core 4.2, the single tube was replaced by a double tube through which moderator and fuel pebbles could be dropped simultaneously.

Reactivity is controlled using a fixed but withdrawable control rod (WCR) and a moveable automatic control rod (ACR). The WCR consists of two concentric stainless steel tubes inserted through most of the core. The automatic control rod consists of a copper bar with a rectangular cross section suspended in an aluminum tube. The bar is tapered in the axial dimension so that it resembles a long thin wedge pointing downward into the core. This rod is partially inserted into the core with its position maintained by reactivity control logic.

The two rods are not located along the same radial-axial plane, so the core has no azimuthal symmetry with which to build an accurate RZ core model. For simplicity, however, PEBBED RZ models were constructed by smearing the rod materials around in a gray curtain. Full 3-D models with two discrete rod channels were also constructed and executed. 


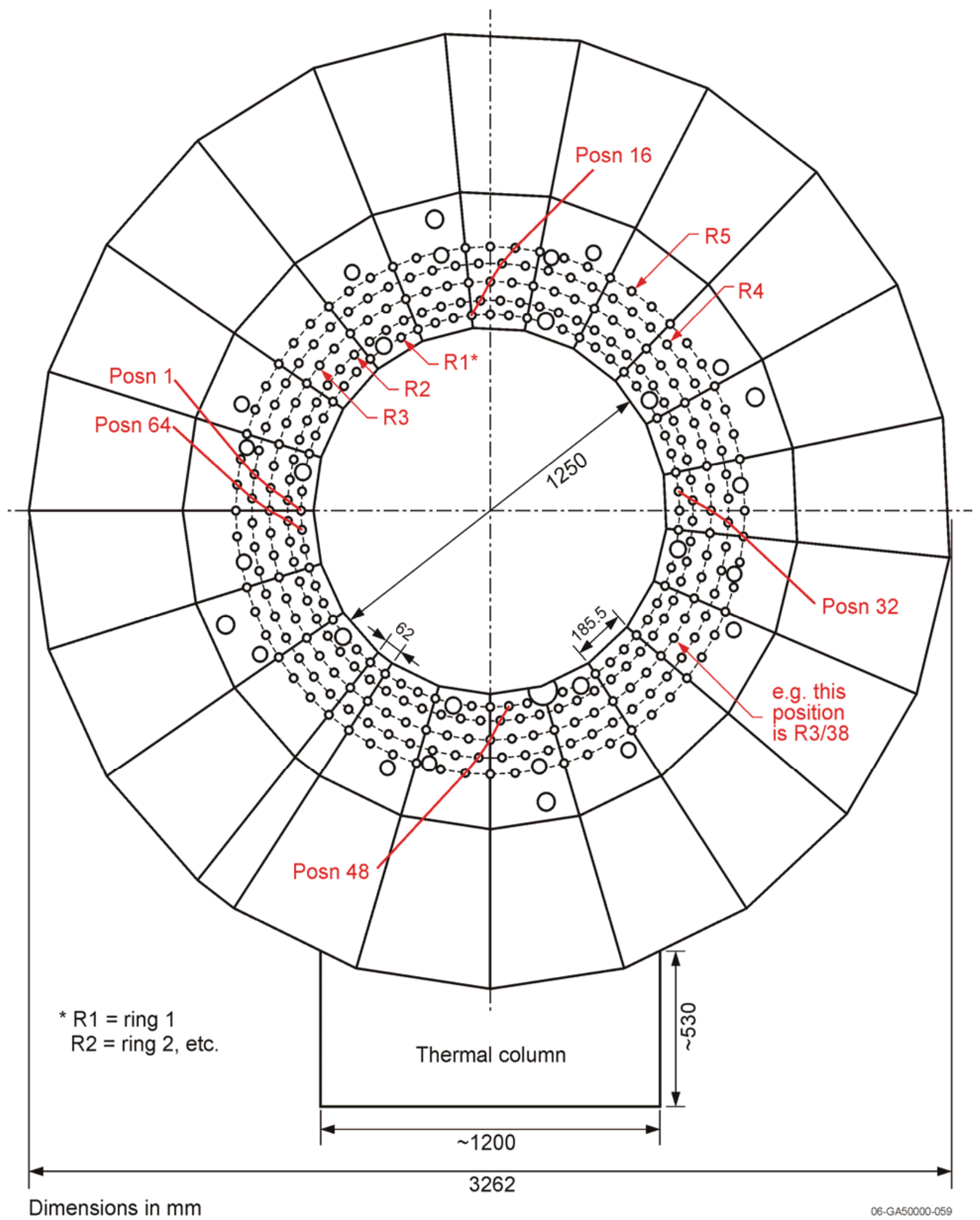

Figure 5. Details of radial reflector and cavity, taken from Reference 6. 


\section{PROTEUS EVALUATION MODEL}

\subsection{Computational Tools and Sequence}

The deterministic transport tools COMBINE-7.0, SCAMP, and PEBBED were deployed to produce axial, radial, and full core flux profiles and eigenvalues. Because almost all PBR power plants feature randomly loaded cores and because PEBBED comprises the foundation of the INL's PBR core design and fuel management capability, it was proposed to validate this suite of deterministic codes using Proteus Core 4 . The core multiplication factor $\left(k_{\text {eff }}\right)$ direct measure of the ability of these tools to reproduce and predict neutronics reaction rates and flux distributions. Flux profiles could also be generated but there is limited data (measurements) against which these profiles can be compared. The principal measure of success of the codes and methods is $k_{\text {eff. }}$ The other computed data can be used for speculation about sources of error.

Deterministic models like these employ a homogenization step in which the model is discretized into regions (nodes) on which a neutron balance is computed. The geometric details within each node are used to generate equivalent diffusion theory parameters for the homogenized regions. The diffusion equation is then solved over the ensemble of homogenized nodes. The process is the same whether the fuel is randomly distributed within the node or arranged in an ordered (crystalline) lattice. The generation of homogenized diffusion parameters for core analysis must account for numerous complex phenomena such as resolved and unresolved resonance interactions, shadowing by neighboring fuel lumps, and selfshielding within those lumps.

The INL has been engaged in the development of deterministic tools for PBR analysis. The PEBBED code is the only tool under development in the U.S. that can simulate neutron transport and burnup in recirculating PBR cores. The COMBINE ${ }^{10}$ spectrum generation code has been modified to compute fewgroup transport and diffusion coefficients for PBR nodal calculations. COMBINE has been incorporated into PEBBED as a subroutine for inline cross section generation. PEBDAN ${ }^{11}$ generates the so-called Dancoff factors for randomly dispersed pebble bed fuel, which are used to account for the spatial shadowing of arrays of fuel lumps. In addition to these codes, the SCAMP ${ }^{12} 1$-D discrete ordinates transport code was used to coalesce few-group constants from the COMBINE unit cell results for the different spectral regions in the mode.

COMBINE-7 solves the 0-D B-1 or B-3 approximations to the neutron transport equation in a unit cell (node) with a buckling correction to capture leakage out of the cell. COMBINE-7 uses ENDF/B-VII data libraries processed with NJOY9932 to solve for the flux over the entire energy range (2E7 to 1E-5 $\mathrm{eV})$. This avoids the limitation of many legacy unit cell spectrum codes that have separate thermal and fast spectrum modules and are unable to treat upscattering and low-energy resonances simultaneously. COMBINE-7 uses the Bondarenko method for treatment of the unresolved resonance region and either the Bondarenko or Nordheim numerical method for resolved resonances. The buckling values are supplied externally, usually from the diffusion calculation in an iterative sequence. The double heterogeneity of the fuel (particle and pebble lumping) is addressed using separate Dancoff factors for the pebbles and TRISO particles. PEBBED exploits the rigorous method of computing Dancoff factors for randomly distributed pebbles and particles developed by Kloosterman and Ougouag and implemented in the PEBDAN code. ${ }^{11}$ Although the cell homogenization algorithm in COMBINE-7 does not preserve the interpebble leakage rates when computing diffusion coefficients, the correction developed by Lieberoth and Stojadinovic ${ }^{13}$ is applied to adjust these values to account for interpebble streaming. Also, the streaming of neutrons across void regions such as the gas plenum above the pebble bed is not treated accurately with cell codes such as COMBINE. Gerwin and Scherer ${ }^{14}$ developed an analytical treatment that yields diffusion coefficients for the gas plenum between the top of the core and the top reflector. These values are supplied in the PEBBED input and replace those generated using COMBINE or SCAMP. 
SCAMP solves the 1-D, discrete ordinates (Sn) approximation to the neutron transport equation in Cartesian or cylindrical geometry. SCAMP accepts the homogenized unit cell cross sections generated with COMBINE for each 1-D node and solves for the flux distribution along the dimension. The flux distribution can then be used to coalesce diffusion theory parameters over space and energy to yield new nodal diffusion parameters. Because Sn transport accounts for highly anisotropic scattering, this approximation is more accurate than that obtained from diffusion theory, even when the internode leakage is captured using buckling. Thus, while the core solution can be obtained with PEBBED and COMBINE alone, greater accuracy can be achieved with an intermediate $\mathrm{Sn}$ transport calculation.

With the few-group nodal parameters supplied by COMBINE or the COMBINE-SCAMP sequence, full core flux profiles and eigenvalues can be computed using PEBBED. The complete PROTEUS Core 4.2 simulation was performed using the capabilities of these tools in their 2008 developmental state and does not reflect recent improvements.

\subsubsection{Computational Sequence}

1. From pebble and geometrical data reduced from the benchmark documents (see Appendix A-2 and A-3). Masses and volumes of structures within each node were converted to number densities. PEBDAN was run to generate spatially varying packing fraction and Dancoff factors. These were inserted into the COMBINE unit cell input deck.

2. A COMBINE unit cell model was constructed for the fuel region (pebble bed) consisting of a single pebble surrounded by a mixture of graphite and moist air representing a surrounding moderator pebble and void (See Figure 6). Smeared number densities (Appendix A-2) were computed for the homogeneous cell. The Nordheim Integral Treatment option in COMBINE was used for resonance cross sections and the $\mathrm{ABH}$ method was used for thermal self-shielding. COMBINE generates a 167-group spectrum from NJOY nuclear data libraries. A user-specified buckling term was manipulated to achieve a COMBINE multiplication factor of 1 (a critical spectrum. The 167-group COMBINE structure was reduced to 99 groups for SCAMP and 16 groups for PEBBED (see Appendix A-1).

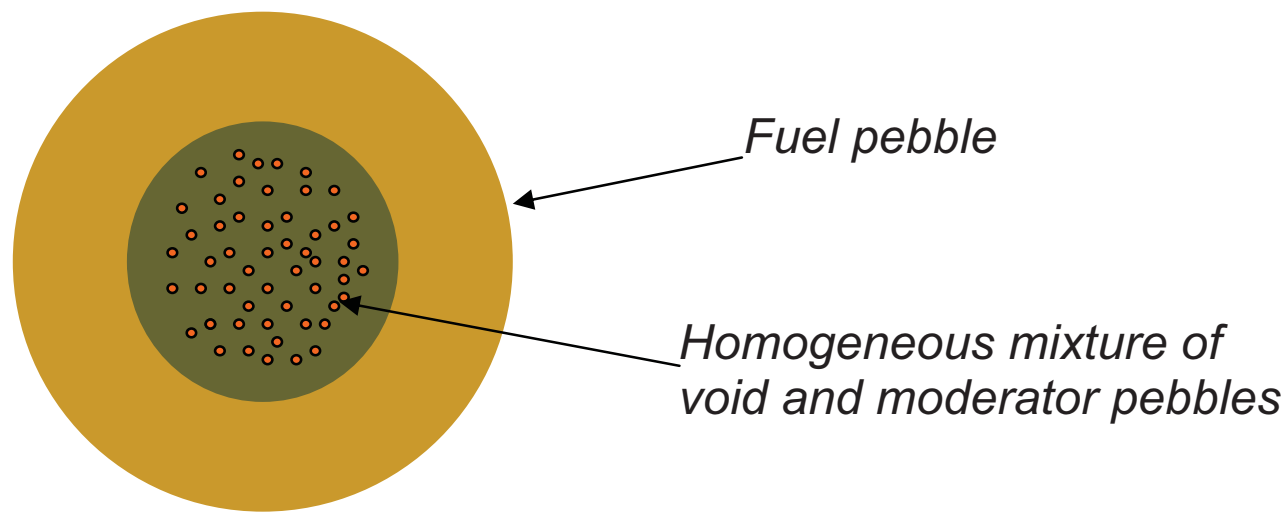

Figure 6. COMBINE unit cell model.

3. Ninety-nine group cross sections for all macroscopic material mixtures generated by COMBINE were used in 1-D radial or axial models of the PBR core. The radial models included the core, the radial reflector, a control rod annulus, and a concrete vessel. The axial models included bottom and top reflectors, the core region, and the gas plenum above the core. For comparison, identical radial and axial models were constructed for PEBBED diffusion analysis along with the SCAMP transport analysis. The SCAMP discrete ordinates code solved the 1-D transport equation and coalesced the cross sections to 16 groups in each broad region (node). The Sn treatment in SCAMP had some 
difficulty with the void region so graphite was added at $3 \%$ of the total volume to avoid nonphysical flux values.

4. These node-averaged cross sections were inserted into the PEBBED 1-D, RZ, and 3-D models of the core. Diffusion coefficients were hand computed for the void region using the method of Gerwin and Scherer. In the core and some reflector nodes, diffusion coefficients from the SCAMP 1-D radial and axial analyses were provided to PEBBED as directional diffusion coefficients. The 1-D model results (flux and $k_{\text {eff }}$ ) were compared to the corresponding SCAMP results. Core eigenvalue results from the 2-D (RZ) and 3-D models were compared to the benchmark experimental value.

5. Variations on the base model included: models without control rods, analysis with a single diffusion coefficient rather than the separate (directional) values for the radial and axial direction, analysis with the Sn-computed diffusion coefficients rather than the Gerwin and Scherer values, and core models in which the packing fraction and Dancoff factors were assumed constant vs. those in which the packing fraction and Dancoff factors varied in the radial direction.

Figure 7. Illustrates the computational sequence used in this study.

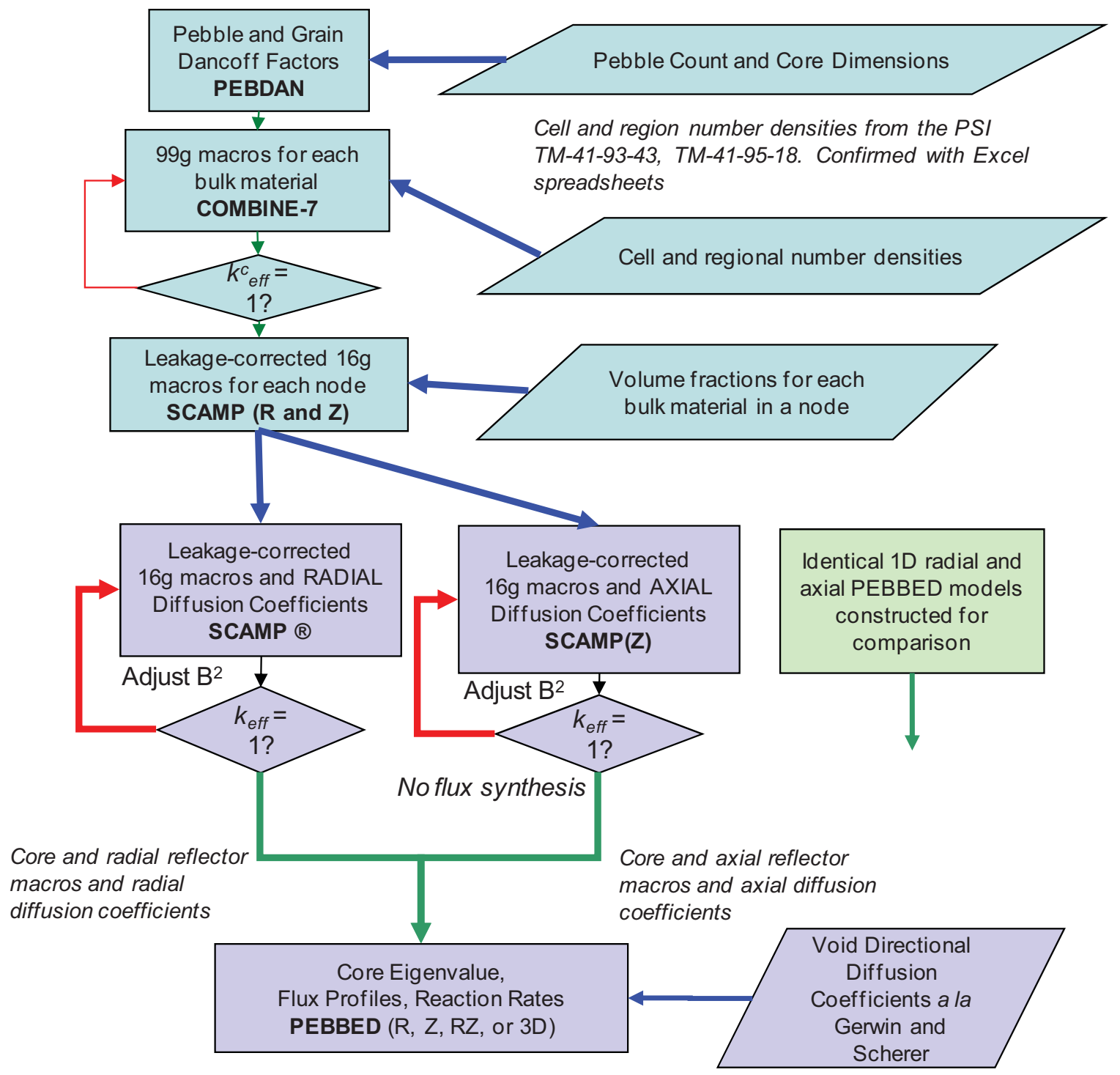

Figure 7. Computational algorithm for the deterministic simulation sequence. 


\subsection{Computational Models}

Figure 8 shows the RZ model of the critical core with the SCAMP and PEBBED nodalization. 1-D radial models were constructed for each row of nodes and 1-D axial models were constructed for each column. For the RZ and 3-D PEBBED models, the diffusion coefficients generated in the axial SCAMP models were fed to PEBBED as axial (directional) diffusion coefficients. Likewise, diffusion coefficients from the radial SCAMP calculations were read in as radial diffusion coefficients in PEBBED.

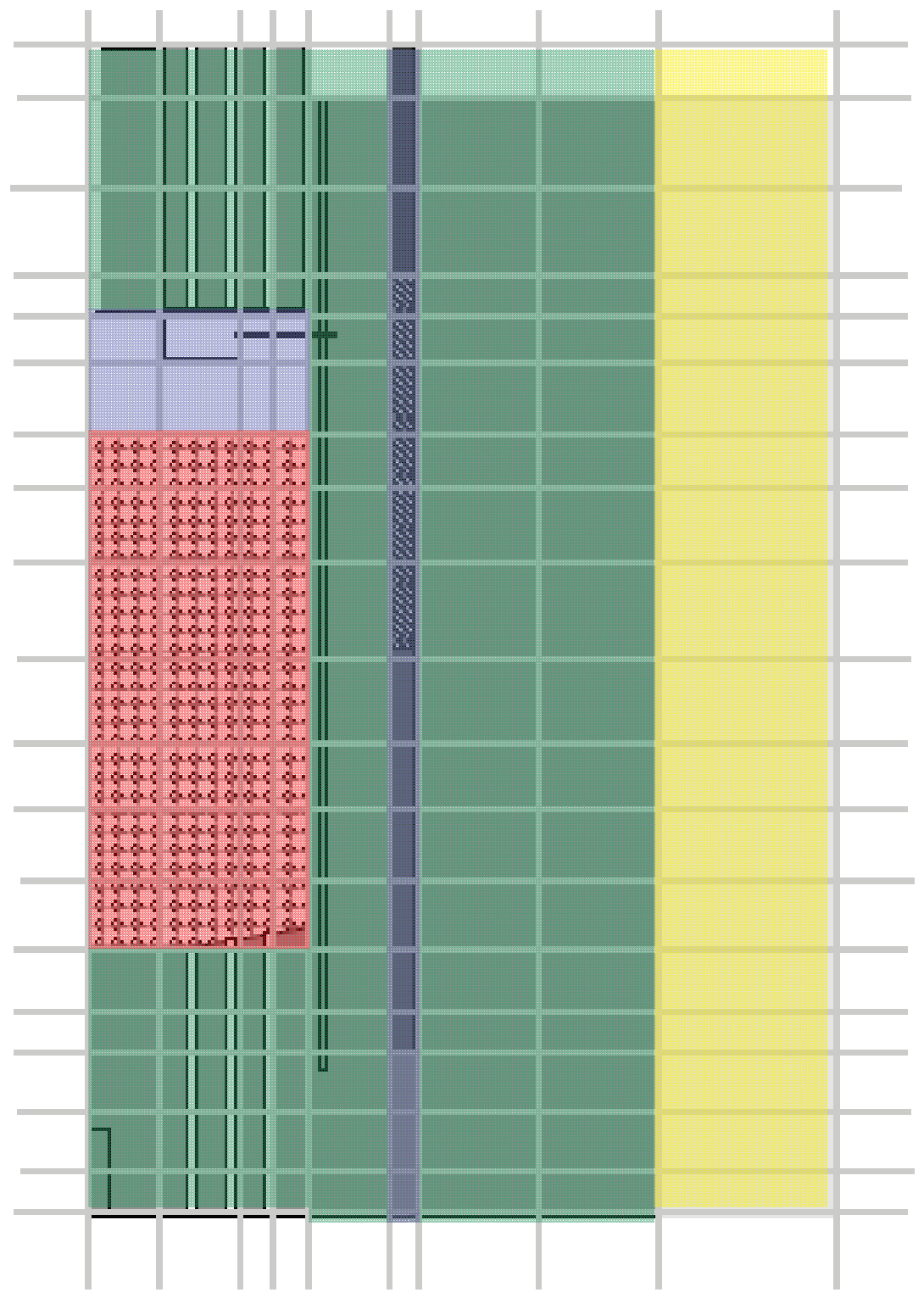

Figure 8. Nodalization of the PEBBED RZ core model. 


\subsection{Software}

COMBINE version 7.0 was used to generate multigroup diffusion and transport cross sections from ENDF/B v7 nuclear data libraries. COMBINE is a portable B-1 or B-3 spectrum generation code that exploits the Bondarenko and Nordheim Integral algorithms for neutron slowing down in the resonance region. For direct computation of few-group diffusion constants, COMBINE 7.0 is called as a subroutine in PEBBED with local nuclide densities and temperatures written to COMBINE input files by PEBBED. Inter-zone leakage, which effects the slowing down spectrum, is provided by PEBBED as groupwise buckling terms. COMBINE 7.0 was developed from COMBINE v6.02 with NGNP funding with specific modifications for application to high temperature reactor. COMBINE was written in FORTRAN 90 for execution on a Windows personal computer or on the high performance computing cluster.

For the 1-D transport simulations, 99-group cross sections were computed with COMBINE and inserted into SCAMP input files. SCAMP (CCCM F00710) solves the discrete ordinates (Sn) approximation to the 1-D Boltzmann transport equation in Cartesian, cylindrical, and spherical geometries. SCAMP does not read nuclear data libraries but accepts material cross sections in its input files generated from a code such as COMBINE. SCAMP coalesces cross sections from a fine spatial and energy resolution model into a coarse (nodal), few-group model corresponding to nodes in the whole core diffusion model. SCAMP was written in FORTRAN-77 and runs on either a UNIX workstation or Windows persona computer. For this study, the PC version was used. SCAMP is maintained and used by the Advanced Test Reactor Programs Engineering organization.

PEBBED version 5 solves the neutron diffusion and depletion equations in 1,2, and 3 dimensions and in Cartesian and cylindrical coordinates. Few-group cross sections are input manually (as from SCAMP) or generated online with calls to COMBINE. PEBBED runs on a Windows PC and on the high performance computing cluster. The 1-D and 2-D models were run on a PC. The 3-D models were developed and tested on the PC but complete execution was performed on the HPC cluster. The archival version of PEBBED is maintained on the HPC cluster using the Tortoise Subversion version control software. 


\section{RESULTS AND INTERPRETATION}

\subsection{Dancoff Factor Calculation}

Stochastically loaded pebble beds feature a variable packing density. The packing fraction tends to zero at the reflector where the pebbles maintain only point contact with the reflector walls. The packing fraction then oscillates, moving away from the wall. About 4-5 pebble diameters into the bed, the packing fraction shows only statistical variations. This profile was computed by the PEBDAN code and is shown in Figure 9.

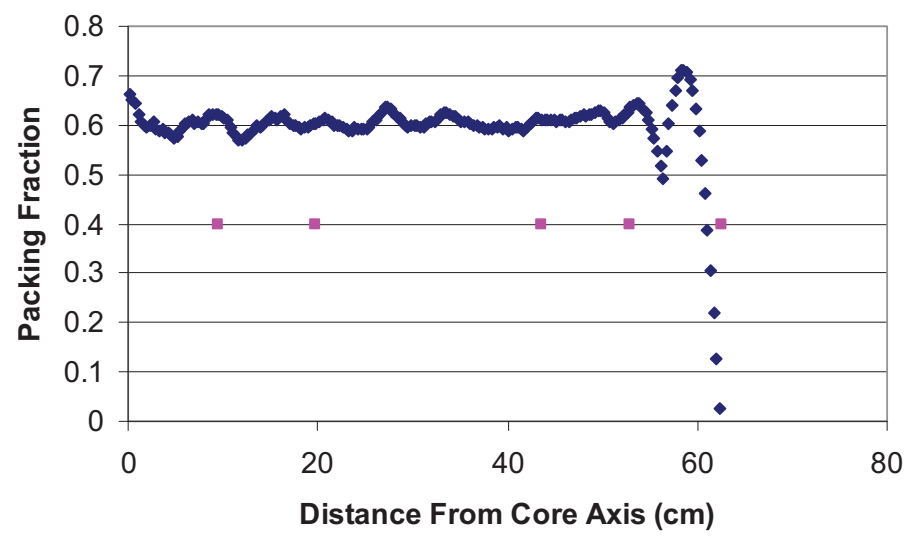

Figure 9. Radial variation in pebble packing fraction as computed by PEBDAN.

The magenta points in the diagram indicate only the location of the node radial boundaries. PEBDAN computes local packing fractions and Dancoff factors which were then averaged over each node to yield values for insertion into the COMBINE models. Figure 10 shows the variability of intrapebble and interpebble Dancoff factors in the radial and axial directions.

The Dancoff factors vary by about $20 \%$ along the axial dimension in the bulk of the core. The values drop off considerably near the top of the pebble bed (near the void), but as this is a region of low flux, this trend is not considered to be of consequence in the overall analysis. The radial variation in the values was considered to be significant enough to be reflected in the COMBINE calculations. For the purposes of the COMBINE spectrum analysis, the Dancoff factors were different for each radial channel (column) as shown in Table 1.

The mean packing fraction of the core, as determined experimentally from the mean bed volume and number of pebbles, equaled 0.5853 . The mean fraction computed form the PEBDAN calculation was 0.5839 . 
Axial InterPebble Dancoff Variation

$(0=$ top of core, mean $=0.0255)$

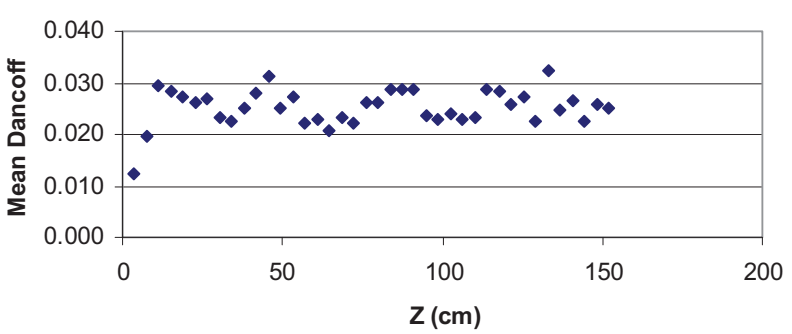

Radial InterPebble Dancoff Variation

$(0=$ core axis, mean $=0.0255)$

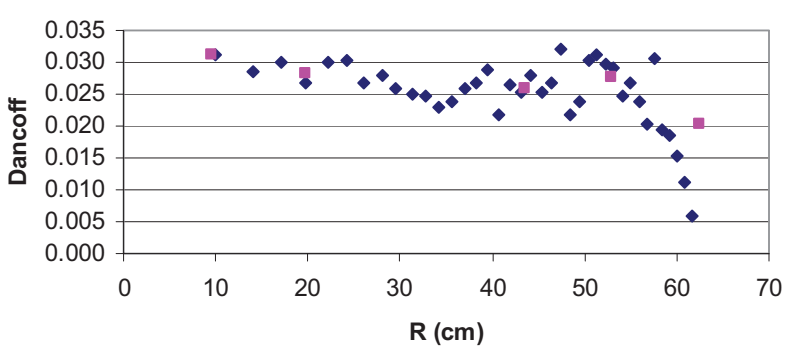

Axial IntraPebble Dancoff Variation

$(0=$ top of core, mean $=0.1746)$

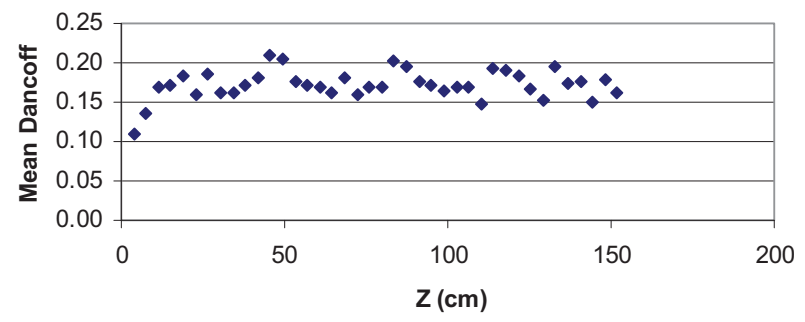

Radial IntraPebble Dancoff Variation

$(0=$ core axis, mean $=0.1746)$

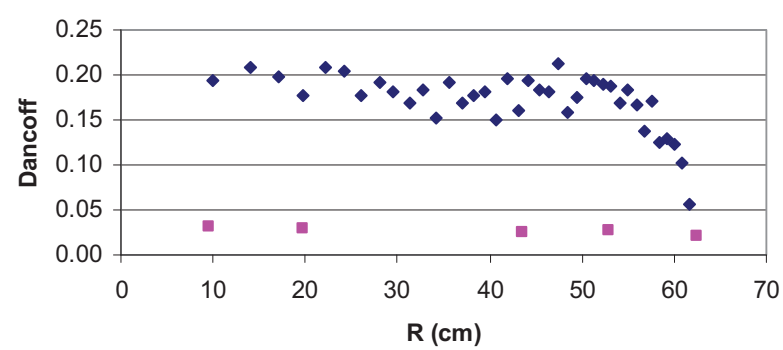

Figure 10. Dancoff factors along the radial and axial dimensions.

Table 1. Dancoff factor for the five radial zones.

\begin{tabular}{|c|c|c|c|}
\hline \multirow{2}{*}{$\begin{array}{c}\text { Radius of Outer } \\
\text { Boundary }(\mathrm{cm})\end{array}$} & \multirow{2}{*}{ Packing Fraction } & Dancoff Factor \\
\cline { 3 - 4 } & 0.6040 & 0.1938 & 0.0312 \\
\hline 9.5 & 0.5991 & 0.1926 & 0.0283 \\
\hline 19.8 & 0.6039 & 0.1777 & 0.0259 \\
\hline 43.5 & 0.6154 & 0.1871 & 0.0277 \\
\hline 52.9 & 0.5433 & 0.1394 & 0.0202 \\
\hline 62.5 & & & INTER \\
\hline
\end{tabular}

\subsection{1-D Flux Comparisons}

Identical 1-D SCAMP and PEBBED models of selected rows and columns, fed by the same COMBINE nodal cross sections, allow for the comparison of flux profiles as computed from diffusion and transport theories. Other effects studied using these 1-D models include: the nominal treatment of double heterogeneity by COMBINE, different calculations of buckling to represent internodal leakage, and the use of nodal parameters coalesced from the 1-D SCAMP transport models versus those from the leakage-corrected COMBINE unit cell calculation. The plots in Figure 11 and Figure 12 reveal these effects. The data sets were taken from the following radial cases:

- S6 Het-bcr9: SCAMP transport flux (scattering order = 6), Dancoff factors vary in the radial direction (heterogeneous packing), axial row $\# \mathbf{9}$ which includes both control rods

- S6 Hom-bcr9: SCAMP transport flux (scattering order = 6), homogeneous packing fraction, axial row $\#$ 9, which includes both control rods 
- Diff Het Sn: PEBBED Diffusion flux, Dancoff factors vary in the radial direction (heterogeneous packing),, axial row \#9, which includes both control rods, cross sections coalesced from SCAMP Sn transport calculation

- Diff Hom Sn: PEBBED Diffusion flux, homogeneous packing fraction, axial row \#9, which includes both control rods, cross sections coalesced from SCAMP Sn transport calculation

- Diff Het LB: PEBBED Diffusion flux, Dancoff factors vary in the radial direction (heterogeneous packing), axial row \#9, which includes both control rods, cross sections coalesced from COMBINE unit cell calculations with leakage buckling correction from the core calculations

- Diff Het MB: PEBBED Diffusion flux, Dancoff factors vary in the radial direction (heterogeneous packing), axial row \#9, which includes both control rods, cross sections coalesced from COMBINE unit cell calculations with material buckling correction computed from node composition.

Figure 11 shows the fast flux variation in the radial direction with a 'gray curtain' region representing the control rod channels. A log scale is used for the flux to accentuate the differences. Figure 12 shows the corresponding thermal flux. The orange shading indicates the core while the green shading indicates the gray curtain absorber.

There is little difference between the fast flux profiles in the core and inner reflector regions. Diffusion theory departs from transport theory deep into the radial reflector; an expected result given that neutron scattering is forward-peaked after deep penetration through a moderator. The buckling corrections (both leakage and material) improve the diffusion result. However, the diffusion result matches transport theory quite well when the diffusion theory constants are collapsed from the 1-D transport model rather than directly from the unit cell calculation.

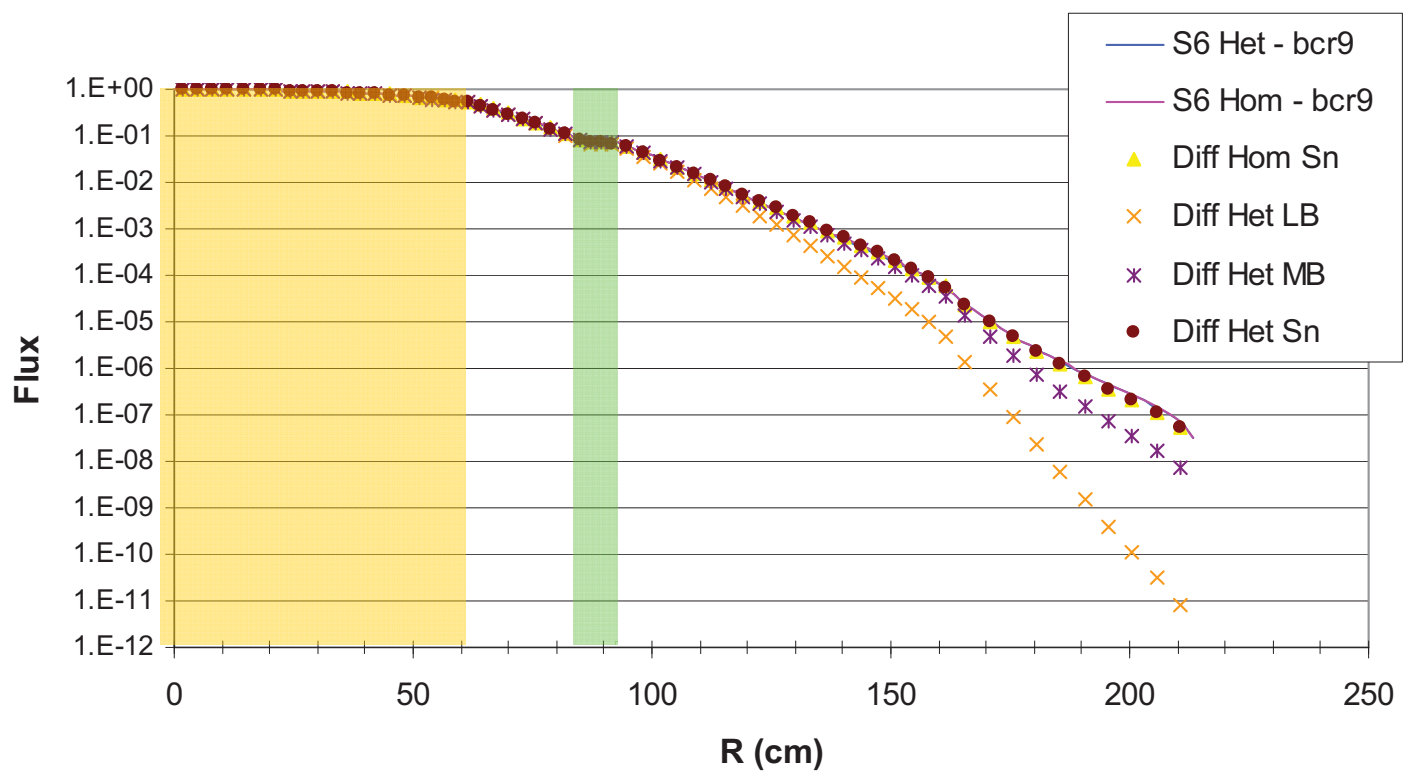

Figure 11. Normalized fast $(>2.38 \mathrm{eV})$ flux profile in radial direction. 


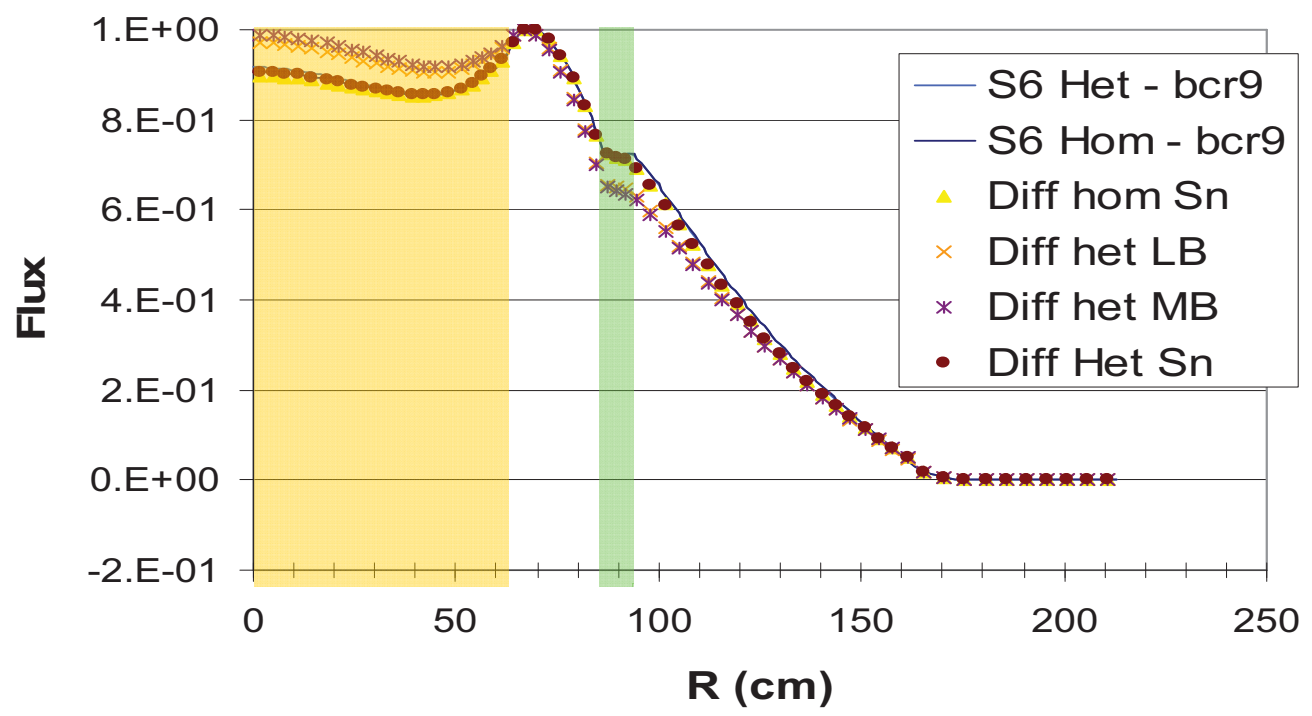

Figure 12. Normalized thermal $(<2.38 \mathrm{eV})$ flux profile in radial direction.

The plot shows differences between diffusion and transport theory in the core region as well as the absorber channel. The core flux computed by transport is higher than that computed using diffusion theory with unit cell cross sections. Also, the transport code computes lower absorption in the control curtain as transport theory captures self-shielding more accurately than diffusion. Diffusion theory works well if the cross sections are computed from the 1-D transport model rather than directly from the unit cell model. This is also reflected in the core multiplication factor $\left(k_{\text {eff }}\right)$ for this case. SCAMP computes a value of 1.13027, whereas PEBBED computes a value of 1.13334. The buckling correction in COMBINE does not significantly improve the COMBINE spectrum.

Using local values of the Dancoff factor does not significantly change the result from the one in which the core-wide mean Dancoff values are used.

Different comparisons were made for the flux along the axial dimension. The following plots show the differences between using Sn scattering order 6 and 8, and the difference in profiles when the top gas plenum is filled with graphite. All of these cases assume a homogeneous (constant) packing fraction in the radial direction.

S6 hom: SCAMP Sn order 6 transport flux

DIFF hom: Diffusion flux using cross sections from COMBINE

DIFF NVD: Diffusion flux using cross sections from COMBINE, graphite-filled gas plenum (no void)

S6 NVD: SCAMP S6 transport flux,, graphite-filled top plenum (no void)

S8 hom: SCAMP Sn order 8 transport flux

Figure 13 shows the fast $(>2.38 \mathrm{eV})$ normalized flux profile along the core axis. Figure 14 shows the corresponding thermal flux profile. The blue-shaded region represents the top gas plenum and the orange region represents the core. Graphite reflectors are on both sides. 


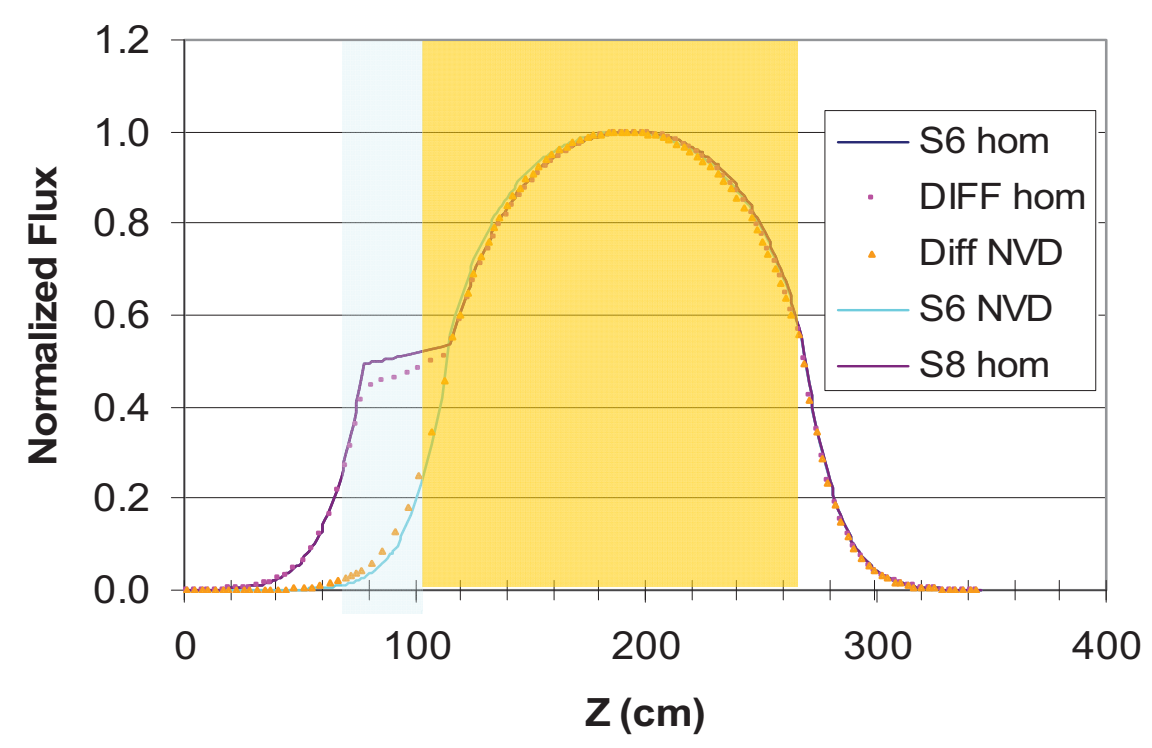

Figure 13. Normalized fast flux along the axial direction.

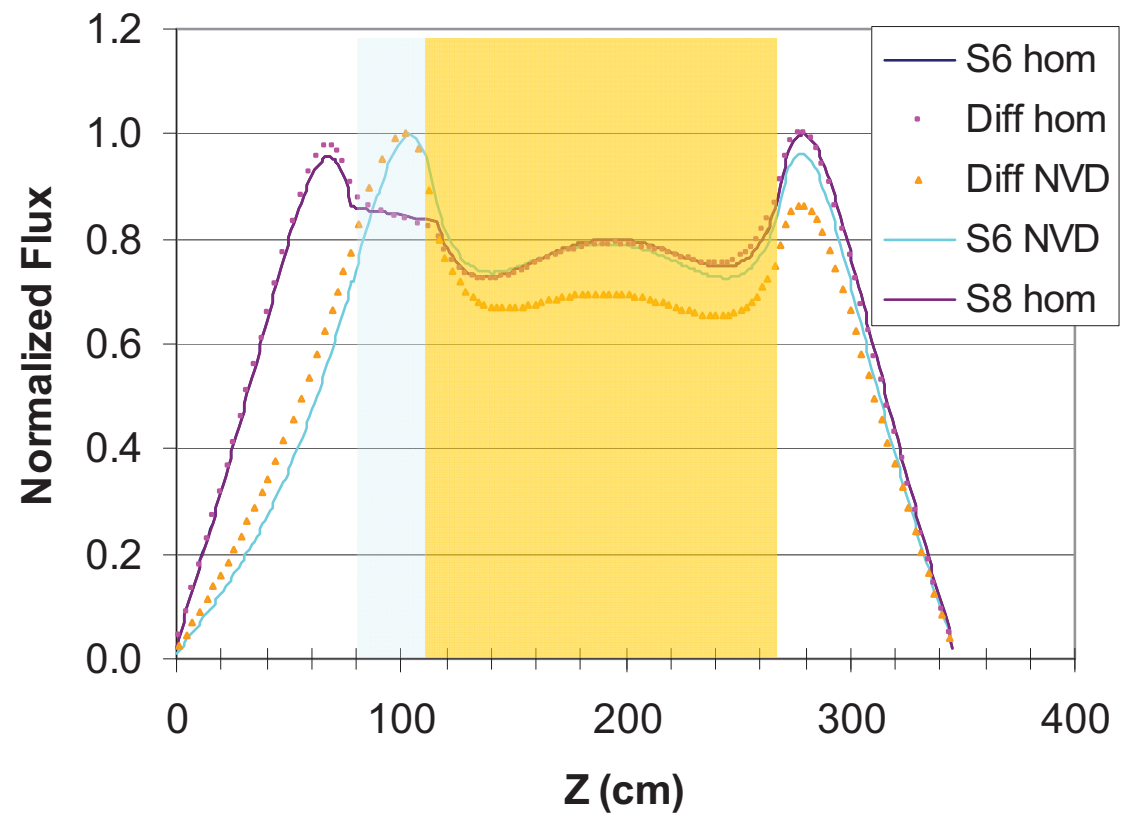

Figure 14. Normalized thermal flux along the axial direction.

Except for a slight difference in the void region, diffusion and transport theory predictions of flux agree well with and without the void above the core. SCAMP computes a value of 1.50145 for the central axis model whereas PEBBED, using cross sections collapsed from the SCAMP model, computes a value of 1.49242. The presence of the void raises the thermal flux in the core equally for both diffusion and transport. There is no appreciable difference between scattering order 6 and order 8 for transport calculations, indicating a lack of any significant scattering anisotropy. These results suggest that diffusion theory with cross sections generated directly from unit cell models works reasonably well in predicting axial flux profiles in the core. 
Although the above plots indicate that radial variability in void packing fraction shows little effect on the spectrum and flux profiles, Figure 15 show that it does have an effect on local power density.

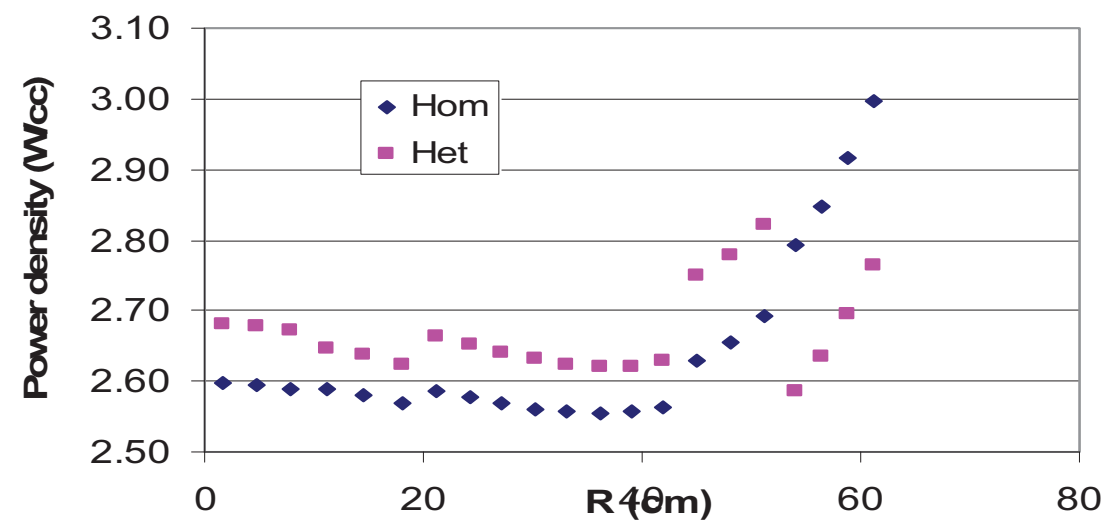

Figure 15. Axially averaged radial power profile: varying vs. constant packing fraction.

Recall that the core is divided into five radial channels in which local packing fractions and Dancoff factors were computed for each channel (Table 1). The effect clearly manifests itself in the radial power profile as discontinuities break the profile into five distinct sections. The dark blue points were those in which the mean core Dancoff factor was for all five regions. The magenta profile is the one in which the local Dancoff values were used for each region. The variation in Dancoff factors has a negligible effect compared to the effect of the average number density, both of which are functions of packing fraction. Nonetheless, these plots indicate that power profiles can be as much as $4-5 \%$ in error, if variations in packing density are not taken into account.

These numbers must be accepted with two cautions. First, the discontinuities in the power trace are a consequence of the somewhat arbitrary dicretization of the radial dimension into five channels over which average values are computed. In reality the packing fraction varies smoothly and so would the power density. Also, this is a simulation of an isothermal core. Actual temperature differences in an operating PBR would alter this profile via temperature feedback effects.

The 1-D results shown above should not be construed as validating calculations. They have not been compared to actual flux profiles in the PROTEUS core. The PEBBED and SCAMP flux profiles were generated using the same unit cell cross sections and algorithms in COMBINE. This cross section generation procedure itself has yet to be validated and is a subject of study in NGNP Methods. These plots do indicate the efficacy of different computational procedures in generating cross sections for diffusion-based core models. They also reveal the sensitivity of the flux to different parameters and techniques.

\subsection{Two and Three Dimensional Results}

A comparison of flux profiles was not performed for multidimensional models because a comparable multidimensional transport model of PROTEUS Core 4.2 has not yet been performed. A 3-D MCNP calculation is planned in the near future, and the results will enable verification of the deterministic analyses performed in this study.

Multidimensional flux profile validation is also not possible because no detailed flux measurements were performed on PROTEUS. Flux measurements were taken at a few selected locations and these can be used as validating data, but the coarse nodalization of diffusion models makes detailed comparisons difficult. A better approach is to model the core with a high resolution MCNP model (pending), validate 
the model using the eigenvalue and flux measurements, and then compare the gross flux profiles of the deterministic analysis (PEBBED-COMBINE) with the MCNP model results. This is not part of this preliminary study but is the next step in the validation process.

This deterministic model can be used to generate the core multiplication factor $\left(k_{\text {eff }}\right)$ of the critical facility, a first and vital step in confirming the accuracy of any reactor physics tool or analysis sequence. By definition, $k_{\text {eff }}=1$ for any reactor operating at constant power. Thus, the PEBBED core eigenvalue should equal 1 if the core models were constructed properly and the cross section generation sequence is correct.

The authors of the Proteus benchmark, however, indicate some departures from this simple approach. A number of minor features of the reactor are difficult to model but still have a non-negligible reactivity effect. The benchmark authors estimated the worth of these features to obtain an adjusted multiplication factor of 1.0129. In other words, not modeling these features would lead to an over-estimation of reactivity by about $\$ 1.76$. Except for the control rods, none of these minor features were modeled in this exercise. The control rods were estimated to have a worth of about $\$ 0.55$. Therefore, the target eigenvalue for the PEBBED core models without control rods is 1.0129 and slightly less with explicit modeling of the rods (about 1.009). These $k_{\text {eff }}$ values thus represent the 'target' eigenvalues for the PEBBED analysis.

\subsubsection{RZ vs. 3-D}

As mentioned at the end of Section 2.2 and indicated in Figure 4, the two control rods were not located on the same RZ plane, nor were the control rods inserted to the same depth. Therefore, the flux profile of the core was inherently asymmetrical. RZ core models, which assume azimuthal symmetry, will thus be inherently inaccurate. Nonetheless, constructing RZ models is a useful step in developing and testing a full 3-D core model. Control rod channels are modeled as a so-called gray curtain, an absorbing cylinder that surrounds the core. The radial locations of the two control rods in the PROTEUS Core 4.2 are close enough that a single gray curtain was used to model both. Figure 8 above shows the PEBBED RZ model with the nodalization. The material assignment for the core is given in Appendix A-6.

\subsubsection{Diffusion Coefficient Considerations}

Variations on the basic RZ model were performed to determine the sensitivity of core calculations to different diffusion coefficients. COMBINE computes a diffusion coefficient from the transport cross section of the local composition. The composition, however, is assumed to be homogeneous and the interpebble neutron streaming is not adequately captured by traditional cross section generation techniques, even with the Dancoff and thermal-self-shielding corrections used in COMBINE. A correction to the diffusion coefficient, developed in Reference 13 presumably accounts for interpebble streaming and changes the diffusion coefficient by about $13 \%$. The effect of this change was observed in this study.

Neutron transport is a directional phenomenon. Although diffusion theory does not capture extreme scattering anisotropy, some improvement in accuracy can be achieved by using different diffusion coefficients for the radial and axial directions in the nodal calculation. For the RZ models developed in this study, cross sections were coalesced from 1-D axial and radial SCAMP models. Because the spectral gradients are far greater in the radial direction, cross sections from the radial SCAMP models were used in the RZ PEBBED models. The diffusion coefficients from the axial SCAMP models, however, were used along with those from the radial SCAMP models. The effect of using these directional diffusion coefficients was assessed by comparing the RZ eigenvalue to that of a model in which a single diffusion coefficient was used for both directions. 
Diffusion theory and many transport approximations have difficulty in regions of low material density (void) such as the gas plenum above the core. Expressions for the radial and axial diffusion coefficients have been developed analytically from transport theory and are detailed in Reference 14. The effect of this correction is also studied briefly here.

\subsubsection{Initial Eigenvalue Results}

Table 2 shows the eigenvalue results for some of the models and variations discussed above. The first four results are for PEBBED models with the control rods and assuming a homogeneous core (no variation in packing fraction and Dancoff factors). All of the RZ models used cross sections coalesced from SCAMP because these were shown in the previous section to yield the best agreement with the SCAMP flux profiles.

The 3-D model did not use the SCAMP cross sections but used the cross sections directly from COMBINE unit cells. Thus, a single diffusion coefficient was used for the axial and radial directions in each node. These were corrected in an iterative manner using the leakage bucklings from the whole core diffusion model. The 3-D model has the advantage that the two control rods could be modeled independently and as discrete azimuthal absorbers rather than as a gray curtain.

Table 2. Eigenvalues of basic 1D, RZ, and 3D homogeneous, rodded core models.

\begin{tabular}{|l|l|}
\hline$R Z$ with single diffusion coefficient & 0.95824 \\
\hline RZ with directional diffusion coefficients & 0.95630 \\
\hline RZ with directional diffusion coefficients and corrected void coefficients & 0.95879 \\
\hline 3-D model with leakage corrected unit cell cross sections & 1.00315 \\
\hline
\end{tabular}

These results are from just a sample of the models that were executed, but they can be used to draw conclusions about the accuracy of the tools and computational approach.

The striking feature is the very low eigenvalue of the RZ models. There is clearly a major deficiency in the method or calculation. Further variations were explored to isolate the deficiency.

- Void treatment. Unit cell calculations are known to generate inaccurate values for the diffusion coefficients in the gas plenum above the core. Results were compared between core using the SCAMP-generated diffusion coefficients and those from the Gerwin and Scherer approach. The difference was found to be minor $(\sim 0.20)$.

- Neutron streaming between pebbles. The homogenization process in codes like COMBINE (scalar flux weighting of different regions around the pebble) captures the reaction rates, but there is a known error in the interpebble streaming that is reflected in a diffusion coefficient error of about $15 \%$ for most PBR systems. The correction proposed by Lieberoth and Stojadinovic was applied to the cross sections generated by SCAMP. This correction lowered the $k_{\text {eff }}$ in the RZ model by about $\$ 1$.

- Assuming a homogeneous core (packing fraction and Dancoff factor) led to a difference of about $\$ 0.35$.

- Removing the control rods had the most dramatic effect, almost \$7. The benchmark estimate puts the rod worth at $\$ 0.55$. Clearly the homogenization of the control rods was either performed with flaws or the method itself is flawed. This is the main (and unacceptably large) error and must be a primary focus for further development.

- The RZ core calculation was repeated using a spectrum iteration method like that used in the 3-D model. COMBINE unit cell models were constructed for each node, except for the control road and concrete nodes in which the macroscopic cross sections from the previous models were used without modification. Zero buckling is assumed initially and the COMBINE cross sections were collapsed 
directly to 16 group constants for the PEBBED models. The core model is executed and new group-wise bucklings are computed for each node. These are fed back to the COMBINE models and the cross sections are updated with the new bucklings to capture the leakage spectrum. This is repeated until the PEBBED eigenvalue converges to within a specified tolerance. Table 3 lists the eigenvalue results from the important cases described above.

Table 3. Eigenvalue results from variations in the method.

\begin{tabular}{|l|c|}
\hline \multicolumn{1}{|c|}{ CASE } & $k_{\text {eff }}$ \\
\hline Experimental & 1.0129 \\
\hline RZ with Homogeneous Packing Fraction, Single Diffusion Coefficient, Rodded & 0.95824 \\
\hline RZ with Homogeneous Packing Fraction, Directional Diffusion Coefficients, Rodded & 0.95630 \\
\hline $\begin{array}{l}\text { RZ with Homogeneous Packing Fraction, Directional Diffusion Coefficients, } \\
\text { Unrodded }\end{array}$ & 1.00259 \\
\hline $\begin{array}{l}\text { RZ with Heterogeneous Packing Fraction, Directional Diffusion Coefficients, } \\
\text { Unrodded and Lieberoth Streaming Correction }\end{array}$ & 1.00007 \\
\hline RZ with COMBINE Cross sections - Leakage Buckling & 1.04924 \\
\hline RZ with COMBINE Cross sections - Material Buckling & 1.03766 \\
\hline
\end{tabular}

\subsubsection{Other Results}

A comparison of the 1-D model results indicates very good agreement between the homogeneous discrete ordinates ( $\mathrm{Sn}$ ) and diffusion calculations. The heterogeneous diffusion model results agree well with the homogeneous result, not with the heterogeneous Sn model (Figure 3). The buckling feedback models yield good agreement with the homogenous Sn model in the core, but grows increasingly inaccurate deep into the reflector. Transport theory clearly reveals physics at the core-reflector boundary that diffusion theory cannot seem to capture. These results will need to be confirmed and explored further.

The axial 1-D models yield fair agreement between the Sn and diffusion models. In one variation however, the gas plenum was replaced with graphite (NVD). The diffusion model seems to be much more affected by the void than the discrete ordinates model.

\subsubsection{General Observations and Recommendations}

Observations from this study include:

- Out of the box (and assuming that the control rod node was homogenized correctly), INL's deterministic neutronics tools can yield reasonable accuracy as long as the reactor doesn't have any strong absorbers in the reflector, i.e. a different control rod treatment is required, at least for RZ calculations.

- COMBINE calculations consumed the bulk of the CPU time. Critical buckling searches exacerbate this issue.

- As implemented, spectral iterations without a boost from explicit transport calculations are not accurate (but using the material buckling is better than using the leakage-derived bucklings).

- There is benefit to be gained in modeling local packing/Dancoff variations, especially with regard to power profiles. 
- The interpebble streaming correction to diffusion coefficients is significant and should be implemented.

\subsubsection{Gaps and Proposed Remediation}

Based on this study, the following gaps and recommendations are proposed:

- Develop a randomly packed unit cell model with MCNP for confirming COMBINE calculations

This will enable the computational verification of the COMBINE slowing-down and resonance treatment. Key reaction rates can be compared to test the accuracy of the spectrum calculations which are the basis of few-group cross section generation.

- Confirm and correctly implement an interpebble streaming correction

The diffusion coefficients generated in the traditional homogenization procedure do not accurately effect the streaming of neutrons between pebbles. The correction proposed by Lieberoth [13] has been implemented into both SCAMP and COMBINE but it needs to be validated against suitable benchmarks.

- Confirm and correctly implement a void treatment

Because of the lack of scattering in the upper pebble bed plenum, diffusion theory is inaccurate and even transport codes have difficulty converging on a physical solution for near void material compositions. Gerwin and Scherer [14]]developed and analytical expression for the diffusion coefficient in the upper plenum. Their expression was used for this study in place of the diffusion coefficients generated by COMBINE and SCAMP. The effect is minor but needs to be validated.

- Model local packing/Dancoff variations

The results in this study indicate the variability of the Dancoff factor due to the radial variation in the pebble packing fraction is negligible. There is a considerable effect, however, on the local power density. While this has little impact on the core calculation of a critical, low temperature reactor like HTR-Proteus, the feedback effect may be significant for power reactors and should be addressed in operating PBR safety analyses.

- Implement a proper cross section generation model using 1-D radial transport solutions.

The 1-D results show that very good results can be obtained using diffusion theory if the cross sections are generated using 1-D transport models. The radial transport effects in small thin pebble bed reactors are considerable near the core-reflector boundary and far away from the core. The buckling model is adequate for most core regions and thus can be used for fuel depletion studies as is currently the case in PEBBED and VSOP.

Differences between diffusion and transport flux predictions in the axial direction appear to be minimal and are adequately addressed using axial buckling terms. Thus, very good core simulations can be obtained with cross sections collapsed from 1-D radial transport models, as has been proposed for NGNP physics development. This may substantially reduce the computational effort required to perform full core simulations with transport accuracy. Azimuthal variations, such as those due to single control rod insertions, may require further transport treatments however.

- Develop and implement a decent control rod treatment

Diffusion theory is known to be inadequate near strong absorbers and various ad hoc methods have been employed to treat control rods in PBRs. The problem is especially difficult because the rods are located in the radial reflector where no fission source occurs. This was evident in the results of the R$\mathrm{Z}$ simulations in which the two control rods were modeled as a single gray curtain, itself a poor approximation to the actual reactor. 
- Explore the use of discontinuity factors (approximate values can be generated by the 1-D or synthesized transport solutions)

Further accuracy with regard to radial neutron leakage may be contained by using the 1-D transport calculation to generate so-called discontinuity factors. These factors allow the continuity of the diffusion flux at node boundaries where transport effects are significant and diffusion theory breaks down. The nodal balance equations in PEBBED would need to be modified to accept these factors. If cross sections are generated from 1-D radial transport models, however, there may be no need for this enhancement.

- Develop a multiscale cross section generation algorithm in which TRISO particles are modeled explicitly rather than smeared and corrected using approximate techniques.

The preliminary 3-D model actually yielded a reasonable eigenvalue result. It differed from the experimental value by less than $\$ 0.30$. As this model exploited neither the radial transport leakage correction from SCAMP nor the explicit TRISO model, this result may reflect a cancellation of errors and would need to be further confirmed.

An upgrade to COMBINE is being tested in which the 1-D core radial transport calculation and subsequent cross section coalescing is being tested. This would automate the calculation that was performed using SCAMP in this study.

- All future code modifications and upgrades must be validated with PROTEUS or other real benchmark data.

Given that clean operating pebble bed reactors do not exist (HTR-10 in China is the only operating PBR and its core is now contaminated with fission products), past critical facilities provide the only data for validation of PBR analysis codes like COMBINE and PEBBED. This data must be exploited in full as part of a code validation effort. 


\section{SUMMARY}

This study was the first attempt to truly validate the INL deterministic pebble bed analysis tools. Interesting phenomena were observed but not fully explored. The results indicate some successes (diffusion theory using cross sections coalesced from 1-D transport can yield good results) but also some serious gaps (control rod curtain approximation). Many of these gaps are being addressed in the current NGNP Methods program, specifically: multiscale cross section generation and implementation of a builtin 1-D transport solver in COMBINE that will eliminate the need for separate transport (SCAMP) analysis. This study should be repeated once these developments are completed and implemented into the PEBBED suite. 


\section{REFERENCES}

1. Terry, W. K., H. D. Gougar, and A. M. Ougouag, "Direct Deterministic Method for Neutronics Analysis and Computation of Asymptotic Burnup Distribution in a Recirculating Pebble-Bed Reactor," Annals of Nuclear Energy, Vol. 29, 2002, pp. 1345-1364.

2. Hiruta, H., et al, "CYNOD: A Neutronics Code for Pebble Bed Modular Reactor Coupled Transient Analysis," INL/CON-08-14160, September 2008.

3. Gougar, H., Ougouag, A, and Terry, W. "Validation of the Neutronic Solver within the PEBBED Code for Pebble Bed Reactor Design," Proceedings of the M\&C 2005: International Topical Meeting on Mathematics and Computation, Avignon, France.

4. Gougar, H., Reitsma, F., and Joubert, W. "A Comparison of Pebble Mixing and Depletion Algorithms Used in Pebble-Bed Reactor Equilibrium Cycle Simulation," Proceedings of the M\&C 2009: International Topical Meeting on Mathematics and Computation, Saratoga Springs, NY.

5. International Atomic Energy Agency, Critical Experiments and Reactor Physics Calculations for Low-Enriched High Temperature Gas Cooled Reactors, IAEA-TECDOC1249, Vienna, 2001.

6. T. Williams, "LEU-HTR-Proteus: Configuration Descriptions and Critical Balances for the Cores of the HTR-Proteus Experimental Programme," TM-41-95-18 (version 1), Paul Scherrer Institut, 25 November 1996.

7. D. Mathews and T. Williams, "LEU-HTR-Proteus System Component Description," TM-4193-43 (version 2), Paul Scherrer Institut, 25 November 1996.

8. Terry, W., Wemple, A., Dolphin, B., Evaluation of the HTR-Proteus Pebble Bed Reactor Experiments, INL/EXT-09-14768, Rev 1, September 2009 (HTR-PROTEUS-GCR-ECP-001).

9. F. Reitsma, "The Pebble Bed Modular Reactor Layout and Neutronics Design of the Equilibrium Cycle," Proceedings of PHYSOR 2004 - The Physics of Fuel Cycles and Advanced Nuclear Systems: Global Developments, American Nuclear Society Topical Meeting, Chicago, IL, April 25-29, 2004.

10. Yoon, W., Grimesey, R., Nigg, D, and Curtis, R, "COMBINE7.0 - A Portable ENDF/B-VII.0 Based Neutron Spectrum and Cross-Section Generation Program,” INL-EXT-08-14729, September 2008.

11. Kloosterman and Ougouag, "PEBDAN"

12. Brown, A. W., "SCAMP with Dynamic Storage," INEL Letter Report Br-2-82, March 1982.

13. Lieberoth, J. and Stojadinović, A., "Neutron Streaming in Pebble Beds," Nuclear Science and Engineering: Vol. 76, 1980, pp. 336-344.

14. Gerwin, H., and Scherer, W., "Treatment of the Upper Cavity in a Pebble-Bed High-Temperature Gas-Cooled Reactor by Diffusion Theory," Nuclear Science and Engineering, Vol. 97, 1987, pp. 9-19. 


\section{Appendix A}

\section{Referenced Figures}




\section{Appendix A \\ Referenced Figures}

\section{A-1. Energy Group Structures for Various Models}

\begin{tabular}{|c|c|c|c|c|c|c|c|}
\hline \multirow[b]{2}{*}{ Group } & \multicolumn{3}{|c|}{ Upper Energy $(\mathrm{eV})$} & \multicolumn{4}{|c|}{ Upper Energy (eV) } \\
\hline & COMBINE & SCAMP & PEBBED & Group & COMBINE & SCAMP & PEBBED \\
\hline 1 & $2.00 \mathrm{E}+07$ & $2.00 \mathrm{E}+07$ & $2.00 E+07$ & 42 & $1.23 E+03$ & $1.23 \mathrm{E}+03$ & $1.23 E+03$ \\
\hline 2 & $1.69 \mathrm{E}+07$ & $1.69 \mathrm{E}+07$ & & 43 & $9.61 E+02$ & $9.61 E+02$ & \\
\hline 3 & $1.49 \mathrm{E}+07$ & & & 44 & $7.49 \mathrm{E}+02$ & $7.49 \mathrm{E}+02$ & \\
\hline 4 & $1.35 \mathrm{E}+07$ & $1.35 \mathrm{E}+07$ & & 45 & $5.83 E+02$ & $5.83 E+02$ & \\
\hline 5 & $1.19 \mathrm{E}+07$ & & & 46 & $4.54 \mathrm{E}+02$ & $4.54 \mathrm{E}+02$ & \\
\hline 6 & $1.00 \mathrm{E}+07$ & $1.00 \mathrm{E}+07$ & & 47 & $3.54 \mathrm{E}+02$ & $3.54 \mathrm{E}+02$ & $3.54 \mathrm{E}+02$ \\
\hline 7 & $7.79 \mathrm{E}+06$ & $7.79 \mathrm{E}+06$ & & 48 & $2.75 E+02$ & $2.75 \mathrm{E}+02$ & \\
\hline 8 & $6.07 E+06$ & $6.07 E+06$ & & 49 & $2.14 \mathrm{E}+02$ & $2.14 \mathrm{E}+02$ & \\
\hline 9 & $4.72 E+06$ & $4.72 E+06$ & & 50 & $1.67 E+02$ & $1.67 E+02$ & \\
\hline 10 & $3.68 \mathrm{E}+06$ & $3.68 \mathrm{E}+06$ & $3.68 E+06$ & 51 & $1.30 E+02$ & $1.30 \mathrm{E}+02$ & \\
\hline 11 & $2.87 E+06$ & $2.87 E+06$ & & 52 & $1.01 \mathrm{E}+02$ & $1.01 \mathrm{E}+02$ & \\
\hline 12 & $2.23 E+06$ & $2.23 E+06$ & & 53 & $7.89 E+01$ & $7.89 \mathrm{E}+01$ & $7.89 \mathrm{E}+01$ \\
\hline 13 & $1.74 \mathrm{E}+06$ & $1.74 \mathrm{E}+06$ & & 54 & $6.14 \mathrm{E}+01$ & $6.14 \mathrm{E}+01$ & \\
\hline 14 & $1.35 \mathrm{E}+06$ & $1.35 \mathrm{E}+06$ & & 55 & $4.79 E+01$ & $4.79 E+01$ & \\
\hline 15 & $1.05 E+06$ & $1.05 E+06$ & & 56 & $3.73 E+01$ & $3.73 E+01$ & \\
\hline 16 & $8.21 \mathrm{E}+05$ & $8.21 E+05$ & $8.21 \mathrm{E}+05$ & 57 & $2.90 E+01$ & $2.90 E+01$ & \\
\hline 17 & $6.39 E+05$ & $6.39 E+05$ & & 58 & $2.26 \mathrm{E}+01$ & $2.26 \mathrm{E}+01$ & \\
\hline 18 & $4.98 \mathrm{E}+05$ & $4.98 E+05$ & & 59 & $1.76 \mathrm{E}+01$ & $1.76 \mathrm{E}+01$ & \\
\hline 19 & $3.88 \mathrm{E}+05$ & $3.88 \mathrm{E}+05$ & & 60 & 1.37E+01 & $1.37 \mathrm{E}+01$ & $1.37 E+01$ \\
\hline 20 & $3.02 E+05$ & $3.02 E+05$ & & 61 & $1.07 E+01$ & $1.07 E+01$ & \\
\hline 21 & $2.35 \mathrm{E}+05$ & $2.35 \mathrm{E}+05$ & & 62 & $8.32 E+00$ & $8.32 E+00$ & \\
\hline 22 & $1.83 E+05$ & $1.83 E+05$ & $1.83 E+05$ & 63 & $6.48 E+00$ & $6.48 \mathrm{E}+00$ & \\
\hline 23 & $1.43 E+05$ & $1.43 E+05$ & & 64 & $5.04 E+00$ & $5.04 \mathrm{E}+00$ & \\
\hline 24 & $1.11 \mathrm{E}+05$ & $1.11 \mathrm{E}+05$ & & 65 & $3.93 \mathrm{E}+00$ & $3.93 \mathrm{E}+00$ & \\
\hline 25 & $8.65 E+04$ & $8.65 E+04$ & & 66 & $3.06 \mathrm{E}+00$ & $3.06 \mathrm{E}+00$ & \\
\hline 26 & $6.74 \mathrm{E}+04$ & $6.74 \mathrm{E}+04$ & & 67 & $2.38 E+00$ & $2.38 E+00$ & $2.38 E+00$ \\
\hline 27 & $5.25 E+04$ & $5.25 E+04$ & & 68 & $2.33 E+00$ & & \\
\hline 28 & $4.09 E+04$ & $4.09 E+04$ & & 69 & $2.29 E+00$ & & \\
\hline 29 & $3.18 E+04$ & $3.18 E+04$ & $3.18 \mathrm{E}+04$ & 70 & $2.20 \mathrm{E}+00$ & & \\
\hline 30 & $2.48 \mathrm{E}+04$ & $2.48 E+04$ & & 71 & $2.10 E+00$ & & \\
\hline 31 & $1.93 E+04$ & $1.93 E+04$ & & 72 & $2.00 E+00$ & & \\
\hline 32 & $1.50 \mathrm{E}+04$ & $1.50 \mathrm{E}+04$ & & 73 & $1.90 \mathrm{E}+00$ & $1.90 \mathrm{E}+00$ & 1.9 \\
\hline 33 & 1.17E+04 & 1.17E+04 & & 74 & $1.86 E+00$ & & \\
\hline 34 & $9.12 E+03$ & $9.12 E+03$ & & 75 & $1.78 E+00$ & & \\
\hline 35 & $7.10 \mathrm{E}+03$ & $7.10 \mathrm{E}+03$ & $7.10 E+03$ & 76 & $1.70 \mathrm{E}+00$ & & \\
\hline 36 & $5.53 E+03$ & $5.53 E+03$ & & 77 & $1.60 E+00$ & & \\
\hline 37 & $4.31 E+03$ & $4.31 E+03$ & & 78 & $1.50 E+00$ & $1.50 \mathrm{E}+00$ & 1.5 \\
\hline 38 & $3.35 E+03$ & $3.35 E+03$ & & 79 & $1.44 \mathrm{E}+00$ & & \\
\hline 39 & $2.61 \mathrm{E}+03$ & $2.61 \mathrm{E}+03$ & & 80 & $1.35 E+00$ & & \\
\hline 40 & $2.03 E+03$ & $2.03 E+03$ & & 81 & $1.30 E+00$ & & \\
\hline 41 & $1.58 \mathrm{E}+03$ & $1.58 \mathrm{E}+03$ & & 82 & $1.25 \mathrm{E}+00$ & & \\
\hline
\end{tabular}




\begin{tabular}{|c|c|c|c|}
\hline \multirow[b]{2}{*}{ Group } & \multicolumn{3}{|c|}{ Upper Energy (eV) } \\
\hline & COMBINE & SCAMP & PEBBED \\
\hline 83 & $1.20 \mathrm{E}+00$ & & \\
\hline 84 & $1.15 E+00$ & & \\
\hline 85 & $1.13 E+00$ & & \\
\hline 86 & $1.13 E+00$ & $1.13 \mathrm{E}+00$ & \\
\hline 87 & $1.11 E+00$ & & \\
\hline 88 & $1.09 E+00$ & & \\
\hline 89 & $1.08 \mathrm{E}+00$ & & \\
\hline 90 & $1.07 E+00$ & & \\
\hline 91 & $1.06 E+00$ & & \\
\hline 92 & $1.05 \mathrm{E}+00$ & & \\
\hline 93 & $1.03 E+00$ & & \\
\hline 94 & $1.00 E+00$ & & \\
\hline 95 & 9.90E-01 & & \\
\hline 96 & $9.80 \mathrm{E}-01$ & & \\
\hline 97 & $9.70 \mathrm{E}-01$ & & \\
\hline 98 & 9.50E-01 & & \\
\hline 99 & 9.30E-01 & & \\
\hline 100 & $9.10 \mathrm{E}-01$ & & \\
\hline 101 & 8.90E-01 & $8.90 \mathrm{E}-01$ & 0.89 \\
\hline 102 & 8.76E-01 & & \\
\hline 103 & 8.50E-01 & & \\
\hline 104 & 8.00E-01 & & \\
\hline 105 & 7.50E-01 & & \\
\hline 106 & 7.00E-01 & 7.00E-01 & \\
\hline 107 & 6.83E-01 & & \\
\hline 108 & 6.50E-01 & & \\
\hline 109 & $6.25 \mathrm{E}-01$ & & \\
\hline 110 & $6.00 \mathrm{E}-01$ & & \\
\hline 111 & 5.90E-01 & & \\
\hline 112 & $5.75 \mathrm{E}-01$ & & \\
\hline 113 & 5.50E-01 & 5.50E-01 & \\
\hline 114 & 5.32E-01 & & \\
\hline 115 & 5.00E-01 & & \\
\hline 116 & 4.90E-01 & & \\
\hline 117 & 4.80E-01 & & \\
\hline 118 & 4.75E-01 & & \\
\hline 119 & 4.70E-01 & & \\
\hline 120 & 4.60E-01 & & \\
\hline 121 & 4.50E-01 & & \\
\hline 122 & 4.30E-01 & & \\
\hline 123 & 4.20E-01 & 4.20E-01 & 0.42 \\
\hline 124 & 4.14E-01 & & \\
\hline 125 & 3.80E-01 & & \\
\hline
\end{tabular}

\begin{tabular}{rll} 
& \multicolumn{2}{c}{ Upper Energy $(e V)$} \\
Group & COMBINE & SCAMP \\
126 & $3.60 \mathrm{E}-01$ & \\
127 & $3.50 \mathrm{E}-01$ & \\
128 & $3.40 \mathrm{E}-01$ & \\
129 & $3.30 \mathrm{E}-01$ & $3.30 \mathrm{E}-01$ \\
130 & $3.20 \mathrm{E}-01$ & \\
131 & $3.10 \mathrm{E}-01$ & \\
132 & $3.00 \mathrm{E}-01$ & \\
133 & $2.90 \mathrm{E}-01$ & $2.90 \mathrm{E}-01$ \\
134 & $2.80 \mathrm{E}-01$ & \\
135 & $2.70 \mathrm{E}-01$ & \\
136 & $2.60 \mathrm{E}-01$ & $2.60 \mathrm{E}-01$ \\
137 & $2.50 \mathrm{E}-01$ & \\
138 & $2.40 \mathrm{E}-01$ & \\
139 & $2.30 \mathrm{E}-01$ & $2.30 \mathrm{E}-01$ \\
140 & $2.20 \mathrm{E}-01$ & $2.20 \mathrm{E}-01$ \\
141 & $2.00 \mathrm{E}-01$ & $2.00 \mathrm{E}-01$ \\
142 & $1.80 \mathrm{E}-01$ & $1.80 \mathrm{E}-01$ \\
143 & $1.60 \mathrm{E}-01$ & $1.60 \mathrm{E}-01$ \\
144 & $1.40 \mathrm{E}-01$ & $1.40 \mathrm{E}-01$ \\
145 & $1.20 \mathrm{E}-01$ & $1.20 \mathrm{E}-01$ \\
146 & $1.00 \mathrm{E}-01$ & $1.00 \mathrm{E}-01$ \\
147 & $9.50 \mathrm{E}-02$ & $9.50 \mathrm{E}-02$ \\
148 & $9.00 \mathrm{E}-02$ & \\
149 & $8.50 \mathrm{E}-02$ & $8.50 \mathrm{E}-02$ \\
150 & $8.00 \mathrm{E}-02$ & \\
151 & $7.50 \mathrm{E}-02$ & $7.50 \mathrm{E}-02$ \\
152 & $7.00 \mathrm{E}-02$ & \\
153 & $6.50 \mathrm{E}-02$ & $6.50 \mathrm{E}-02$ \\
154 & $6.00 \mathrm{E}-02$ & $6.00 \mathrm{E}-02$ \\
155 & $5.00 \mathrm{E}-02$ & $5.00 \mathrm{E}-02$ \\
156 & $4.00 \mathrm{E}-02$ & $4.00 \mathrm{E}-02$ \\
157 & $3.00 \mathrm{E}-02$ & $3.00 \mathrm{E}-02$ \\
158 & $2.50 \mathrm{E}-02$ & $2.50 \mathrm{E}-02$ \\
159 & $2.00 \mathrm{E}-02$ & $2.00 \mathrm{E}-02$ \\
160 & $1.50 \mathrm{E}-02$ & $1.50 \mathrm{E}-02$ \\
161 & $1.00 \mathrm{E}-02$ & $1.00 \mathrm{E}-02$ \\
162 & $8.00 \mathrm{E}-03$ & $8.00 \mathrm{E}-03$ \\
163 & $7.00 \mathrm{E}-03$ & $7.00 \mathrm{E}-03$ \\
164 & $5.00 \mathrm{E}-03$ & $5.00 \mathrm{E}-03$ \\
167 & $4.00 \mathrm{E}-03$ & $4.00 \mathrm{E}-03$ \\
& $2.00 \mathrm{E}-03$ & $2.00 \mathrm{E}-03$ \\
$1.00 \mathrm{E}-03$ & $1.00 \mathrm{E}-03$ \\
& &
\end{tabular}




\section{A-2. Material Number Densities for Pebble Bed (Core) Region}

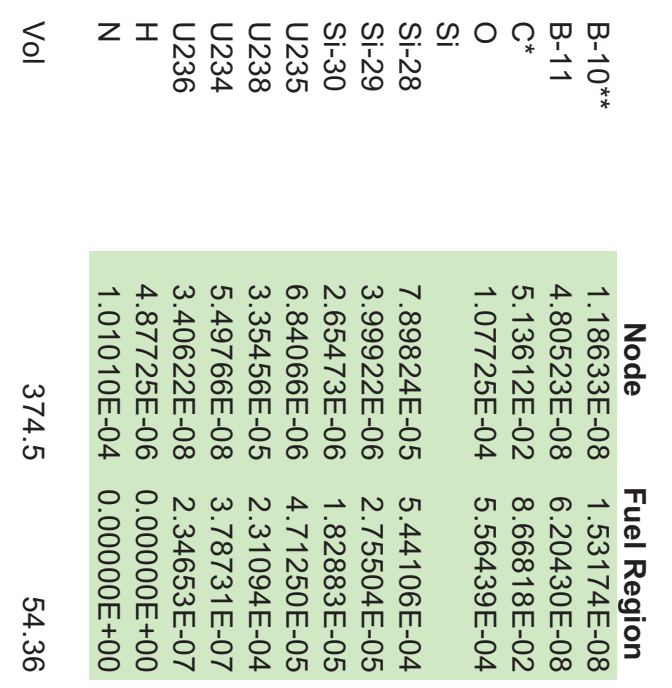

$\omega \nexists \omega \wedge \omega \cap N \omega v$ 히 जี 시이이

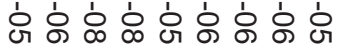

$v \omega n+N \in N \omega \theta$ ○

W N

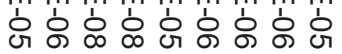
$\checkmark \omega N \omega N \perp \rightarrow N$ G

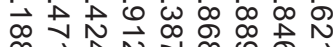

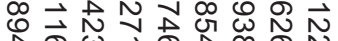

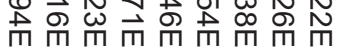

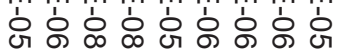
원ำ

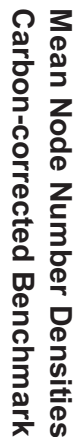

6 or $\rightarrow \rightarrow$ ㄱ. 而皿 웅ㅇํㅇㅇㅇ $\infty$ or or $\rightarrow$ in N $\infty$ ํㅣ 而䒽而 엉 엉 $\checkmark$ or $\rightarrow$ ᄋ ㅅํㅇ

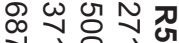
m 잉ㅇㅇㅇㅇ

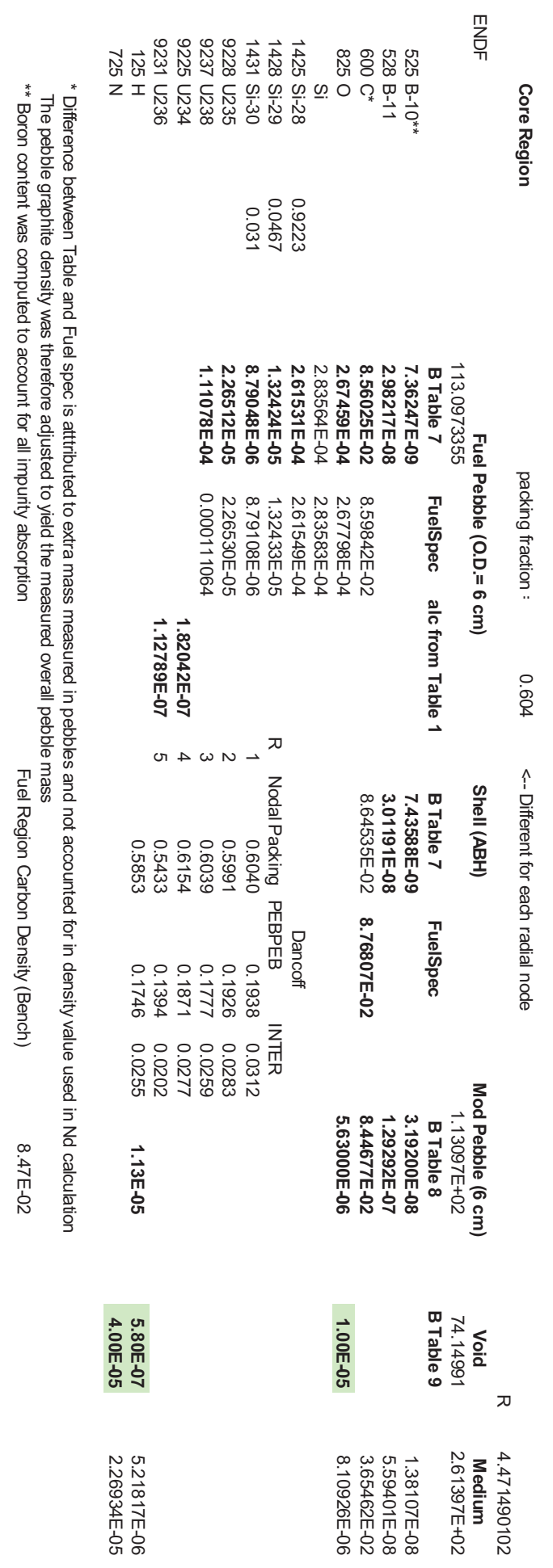




\section{A-3. Number Densities for Noncore Materials}

\section{A-3.1 Smeared Number Densities for the Reflector and Wedge}

Reflector: Mixture of graphite (carbon), boron-10, and boron-11

Conus Wedge: Mixture of fuel and graphite weighted by relative volume in the nodes.

\begin{tabular}{|c|c|c|c|c|c|}
\hline & Reflec & s (Cell) & & & \\
\hline & & & & B Table 12 & FuelSpec \\
\hline 22 & 525 B $-10^{* *}$ & & & $1.59000 \mathrm{E}-08$ & \\
\hline 37 & 528 B-11 & & & $6.40000 \mathrm{E}-08$ & \\
\hline 3 & $600 \mathrm{C}^{*}$ & & & 8.83923E-02 & $8.82424 \mathrm{E}+22$ \\
\hline & Al Hol & (Cell) & & & \\
\hline & & & $a / o$ & B Table 13 & $\mathrm{Nd}$ \\
\hline & B & & & $1.476000 \mathrm{E}-06$ & \\
\hline & 525 & B-10 & 0.199 & & 2.937240 E-07 \\
\hline & 528 & B-11 & 0.801 & & 1.182276E-06 \\
\hline & $\mathrm{Mg}$ & & & $2.034200 \mathrm{E}-03$ & \\
\hline & 1225 & $M g-24$ & 0.7899 & & $1.606815 \mathrm{E}-03$ \\
\hline & 1228 & $M g-25$ & 0.1 & & $2.034200 \mathrm{E}-04$ \\
\hline & 1231 & $M g-26$ & 0.1101 & & 2.239654E-04 \\
\hline 36 & $1325 \mathrm{Al}$ & & & 5.651370 E-02 & 5.651370E-02 \\
\hline 5 & $\mathrm{Si}$ & & & 2.272000E-04 & \\
\hline & 1425 & $\mathrm{Si}-28$ & 0.9223 & & $2.095466 \mathrm{E}-04$ \\
\hline & 1428 & $\mathrm{Si}-29$ & 0.0467 & & $1.061024 \mathrm{E}-05$ \\
\hline & 1431 & $\mathrm{Si}-30$ & 0.031 & & $7.043200 \mathrm{E}-06$ \\
\hline & $2525 \mathrm{Mn}$ & & & $1.452000 \mathrm{E}-04$ & 1.452000 E-04 \\
\hline 23 & $\mathrm{Fe}$ & & & $8.570000 \mathrm{E}-05$ & \\
\hline & 2625 & $\mathrm{Fe}-54$ & 0.059 & & 5.056300 E-06 \\
\hline & 2631 & Fe-56 & 0.9172 & & 7.860404E-05 \\
\hline & 2634 & $\mathrm{Fe}-57$ & 0.021 & & 1.799700E-06 \\
\hline & 2637 & $\mathrm{Fe}-58$ & 0.0028 & & 2.399600E-07 \\
\hline & $\mathrm{Cu}$ & & & $1.260000 \mathrm{E}-05$ & \\
\hline & 2925 & Cu-63 & 0.6917 & & $8.715420 \mathrm{E}-06$ \\
\hline & 2931 & $\mathrm{Cu}-65$ & 0.3083 & & $3.884580 \mathrm{E}-06$ \\
\hline & $3000 \mathrm{Zn}$ & & & $2.440000 \mathrm{E}-05$ & 2.440000 E-05 \\
\hline & $\mathrm{Ga}$ & & & $2.300000 \mathrm{E}-06$ & \\
\hline & 3125 & Ga-69 & 0.6011 & & 1.382530E-06 \\
\hline & 3131 & Ga-71 & 0.3989 & & 9.174700 E- 07 \\
\hline & $\mathrm{Cd}$ & & & $1.420000 \mathrm{E}-07$ & \\
\hline & 4825 & Cd-106 & 0.0125 & & 1.775000 E-09 \\
\hline & 4831 & Cd-108 & 0.0089 & & 1.263800 E-09 \\
\hline & 4837 & Cd-110 & 0.1249 & & 1.773580 E-08 \\
\hline & 4840 & Cd-111 & 0.128 & & 1.817600 E-08 \\
\hline & 4843 & Cd-112 & 0.2413 & & $3.426460 \mathrm{E}-08$ \\
\hline & 4846 & Cd-114 & 0.2873 & & 4.079660E-08 \\
\hline & 4855 & Cd-116 & 0.0749 & & $1.063580 \mathrm{E}-08$ \\
\hline
\end{tabular}

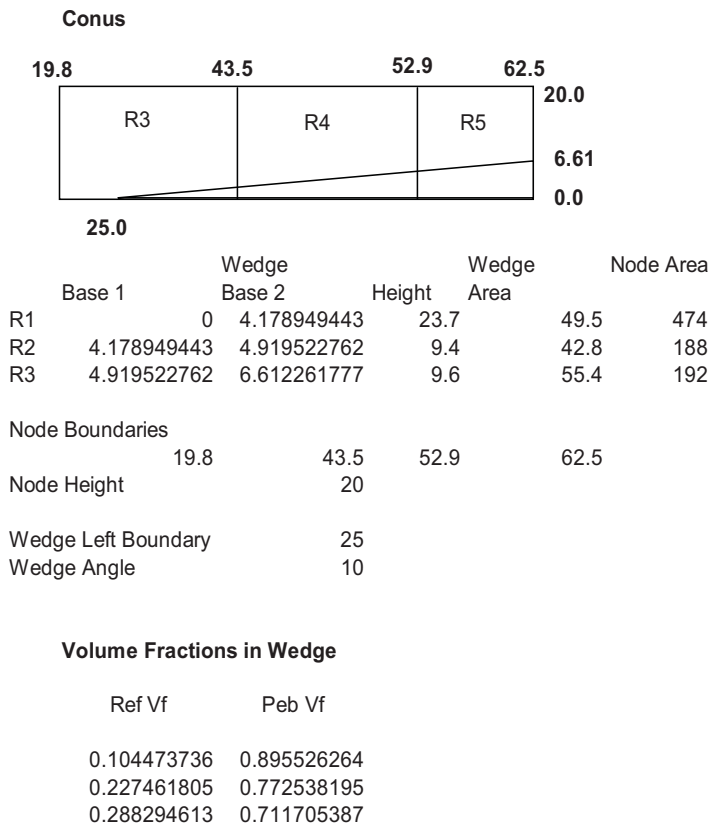

Smeared Number Densities for the Top Reflector and Holder

$\begin{array}{lccccccc}\text { Pure } & 5.80 \mathrm{E}-07 & 1.00 \mathrm{E}-05 & 4.00 \mathrm{E}-05 & 0.0883923 & 1.59 \mathrm{E}-08 & 6.4 \mathrm{E}-08 & 0.0602617 \\ & \mathbf{H} & \mathbf{O} & \mathbf{N} & \mathbf{C} & \mathbf{B}-10 & \mathbf{B}-11 & \text { Al } \\ \text { Al-C-Air 1 } & 1.209 \mathrm{E}-08 & 2.084 \mathrm{E}-07 & 8.337 \mathrm{E}-07 & 8.655 \mathrm{E}-02 & 1.557 \mathrm{E}-08 & 6.267 \mathrm{E}-08 & 0.000 \mathrm{E}+00 \\ \text { Al-C-Air 2 } & 1.600 \mathrm{E}-08 & 2.758 \mathrm{E}-07 & 1.103 \mathrm{E}-06 & 8.429 \mathrm{E}-02 & 1.516 \mathrm{E}-08 & 6.103 \mathrm{E}-08 & 1.109 \mathrm{E}-03 \\ \text { Al-C-Air 3 } & 1.600 \mathrm{E}-08 & 2.758 \mathrm{E}-07 & 1.103 \mathrm{E}-06 & 8.429 \mathrm{E}-02 & 1.516 \mathrm{E}-08 & 6.103 \mathrm{E}-08 & 8.102 \mathrm{E}-04 \\ \text { Al-C-Air 4 } & 1.324 \mathrm{E}-08 & 2.283 \mathrm{E}-07 & 9.134 \mathrm{E}-07 & 8.637 \mathrm{E}-02 & 1.554 \mathrm{E}-08 & 6.254 \mathrm{E}-08 & 0.000 \mathrm{E}+00 \\ \text { Al-C-Air 5 } & 0.000 \mathrm{E}+00 & 0.000 \mathrm{E}+00 & 0.000 \mathrm{E}+00 & 8.086 \mathrm{E}-02 & 1.454 \mathrm{E}-08 & 5.855 \mathrm{E}-08 & 1.787 \mathrm{E}-03 \\ \text { Al:Aluminum Alloy Holder } & & & & & & & \\ \text { C: Graphite } & & & & & & & \\ \text { Moist Air @ 20C } & & & & & & & \end{array}$




\section{A-3.2 Number Densities for Control Rod Absorber}

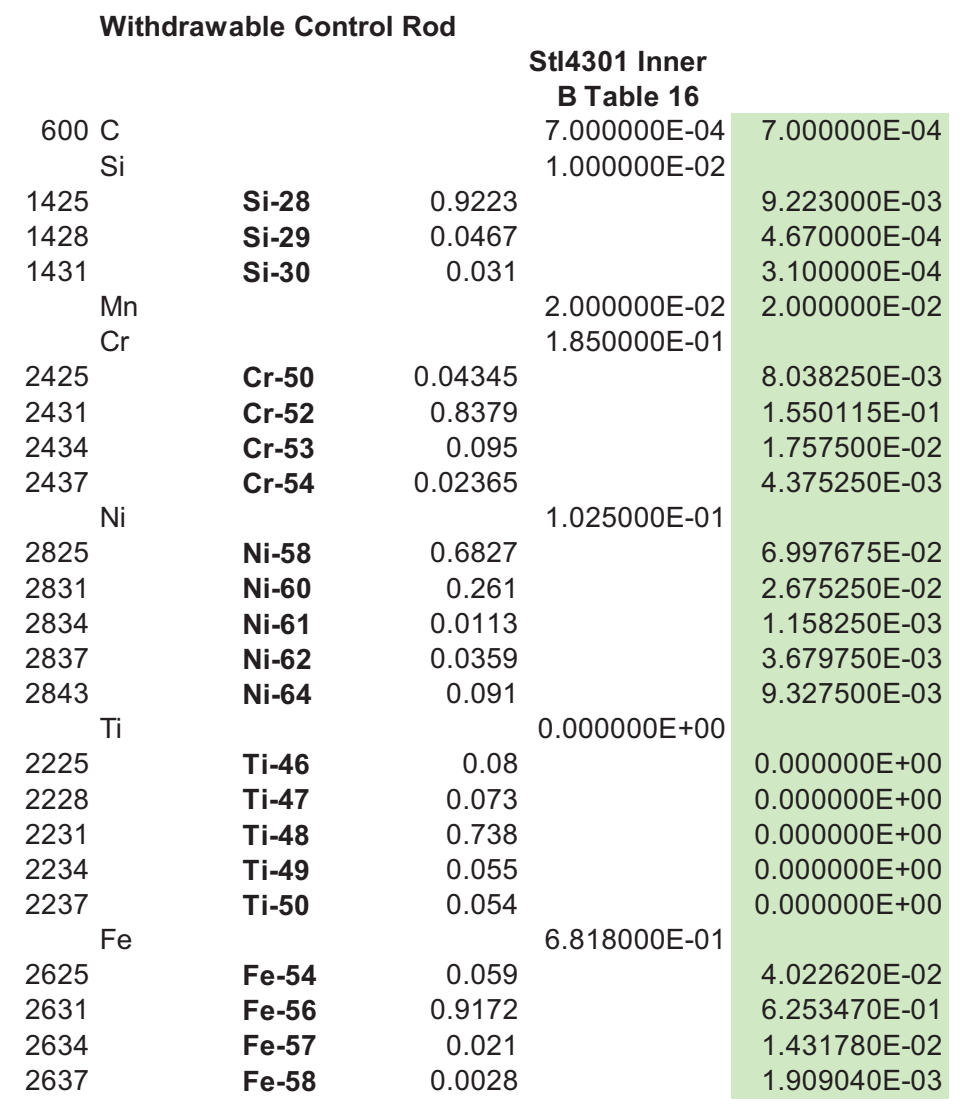

\begin{tabular}{|c|c|}
\hline Stl4541 Outer & \\
\hline B Table 17 & \\
\hline $1.000000 \mathrm{E}-03$ & 1.000000E-03 \\
\hline 1.000000E-02 & $9.223000 \mathrm{E}-03$ \\
\hline & 4.670000E-04 \\
\hline & 3.100000 E-04 \\
\hline $2.000000 \mathrm{E}-02$ & $2.000000 \mathrm{E}-02$ \\
\hline $1.850000 \mathrm{E}-01$ & \\
\hline & 8.038250E-03 \\
\hline & 1.550115E-01 \\
\hline & $1.757500 \mathrm{E}-02$ \\
\hline & 4.375250E-03 \\
\hline 1.025000E-01 & \\
\hline & 6.997675E-02 \\
\hline & 2.675250E-02 \\
\hline & 1.158250E-03 \\
\hline & 3.679750E-03 \\
\hline & $9.327500 \mathrm{E}-03$ \\
\hline $1.000000 \mathrm{E}-03$ & \\
\hline & 8.000000E-05 \\
\hline & 7.300000E-05 \\
\hline & 7.380000E-04 \\
\hline & 5.500000E-05 \\
\hline & 5.400000 E-05 \\
\hline 6.805000E-01 & \\
\hline & 4.014950E-02 \\
\hline & 6.241546E-01 \\
\hline & 1.429050E-02 \\
\hline & 1.905400E-03 \\
\hline
\end{tabular}

\section{Automated Control Rod}

\begin{tabular}{llllll|}
\multicolumn{1}{c}{$\mathrm{Cu}$} & \multicolumn{3}{c}{$8.491097 \mathrm{E}-02$} \\
2925 & $\mathrm{Cu}-63$ & 0.6917 & & $5.873292 \mathrm{E}-02$ \\
2931 & Cu-65 & 0.3083 & & $2.617805 \mathrm{E}-02$ \\
$1325 \mathrm{Al}$ & $\mathrm{Al}-27$ & & 0.060261651 & $6.026165 \mathrm{E}-02$
\end{tabular}




\section{A-3.3 Smeared Number Densities for Control Rod Absorber Regions}
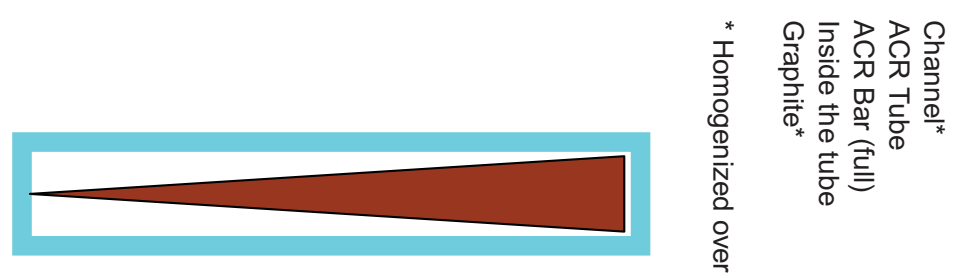

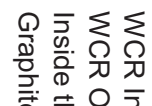

敢离
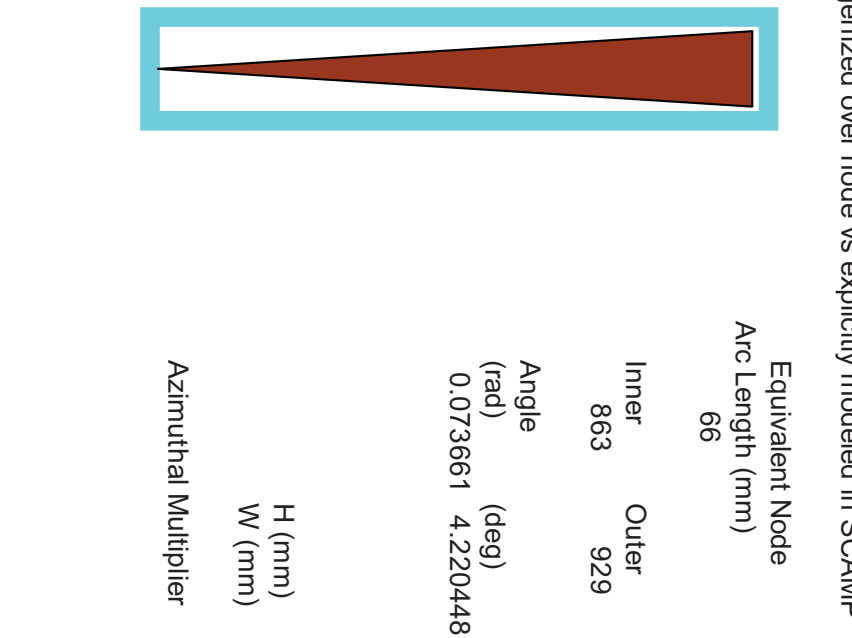

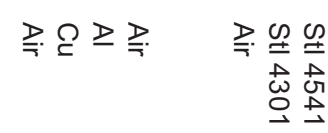

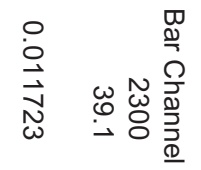

空

- $\overrightarrow{0}+\circ \vec{\perp}$ iा 产

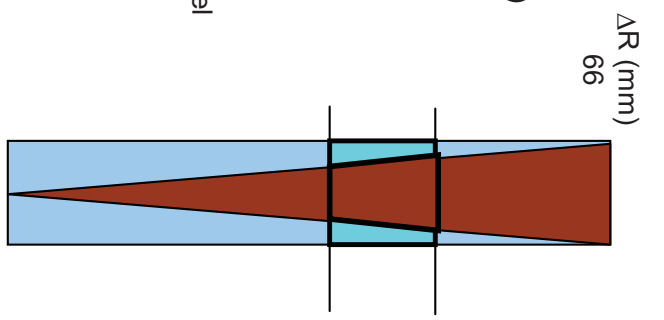

$\omega N$

$\sim N \frac{0}{\sqrt{3}}$
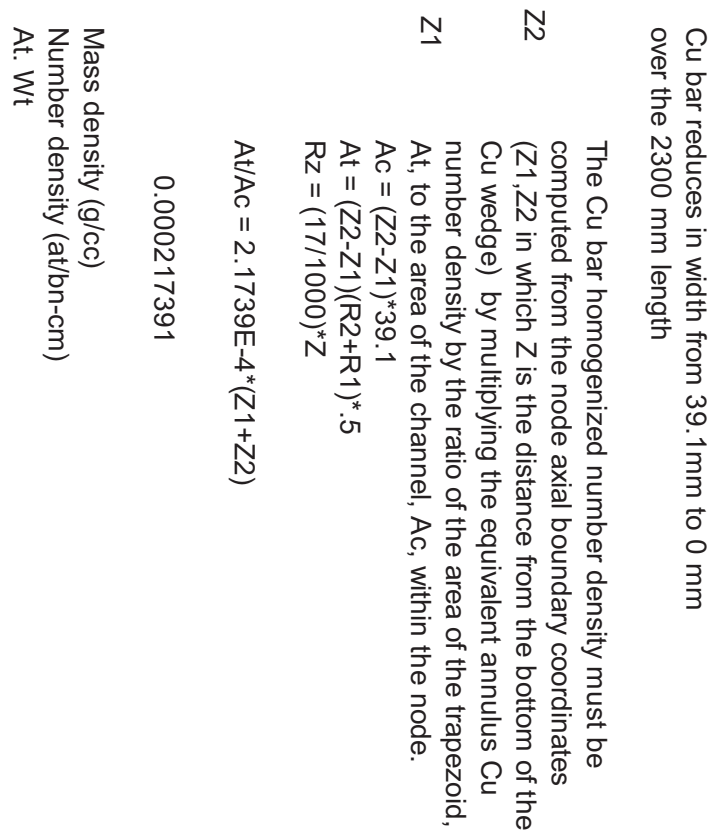

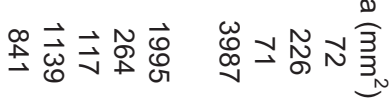

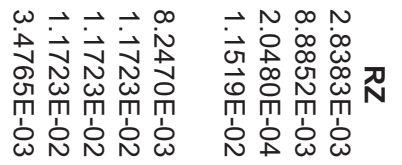

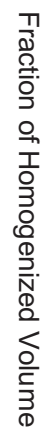




\section{A-3.4 Number Densities for Portland Cement Use in Modeling the Concrete Containment}

\begin{tabular}{|c|c|c|c|c|c|c|c|c|}
\hline & & & & & Elemental & & & Isotopic \\
\hline & w/o & isotope & MW & AW & $\mathbf{N}(\# / \mathrm{bn}-\mathrm{cm})$ & & $a / o$ & $\mathbf{N}(\# /$ bn-cm) \\
\hline Carbon & 0.01 & & & 12.011 & 1.1532E-03 & 0.12011 & 1 & 1.1532E-03 \\
\hline Silicon & 0.337021 & & & 28.0855 & 1.6621E-02 & 9.465403 & 1 & \\
\hline & & 28 & 27.9769 & & & & 0.9223 & 1.5329E-02 \\
\hline & & 29 & 28.9765 & & & & 0.0467 & 7.7618E-04 \\
\hline & & 30 & 29.9738 & & & & 0.031 & 5.1524E-04 \\
\hline Manganese & 0 & & & 54.93805 & $0.0000 E+00$ & 0 & 1 & $0.0000 E+00$ \\
\hline Phosphorus & 0 & & & 30.97376 & $0.0000 E+00$ & 0 & 1 & $0.0000 E+00$ \\
\hline Sulfur & 0 & & & 32.07 & $0.0000 E+00$ & 0 & 1 & $0.0000 E+00$ \\
\hline Nickel & 0 & & & 58.69 & $0.0000 E+00$ & 0 & 0.955 & \\
\hline & & 58 & 57.9353 & & & & 0.6827 & $0.0000 E+00$ \\
\hline & & 60 & 59.9308 & & & & 0.2723 & $0.0000 E+00$ \\
\hline Chromium & 0 & & & 51.996 & $0.0000 E+00$ & 0 & 1 & \\
\hline & & 50 & 49.946 & & & & 0.0435 & $0.0000 E+00$ \\
\hline & & 52 & 51.9405 & & & & 0.8379 & $0.0000 E+00$ \\
\hline & & 53 & 52.9407 & & & & 0.095 & $0.0000 E+00$ \\
\hline & & 54 & 53.9389 & & & & 0.0236 & $0.0000 E+00$ \\
\hline Molybdenum & 0 & & & 95.94 & $0.0000 E+00$ & 0 & 1 & \\
\hline & & 92 & 91.9068 & & & & 0.148 & $0.0000 E+00$ \\
\hline & & 94 & 93.9051 & & & & 0.093 & $0.0000 E+00$ \\
\hline & & 95 & 94.9058 & & & & 0.159 & $0.0000 E+00$ \\
\hline & & 96 & 95.9047 & & & & 0.167 & $0.0000 E+00$ \\
\hline & & 97 & 96.906 & & & & 0.096 & $0.0000 E+00$ \\
\hline & & 98 & 97.9054 & & & & 0.241 & $0.0000 E+00$ \\
\hline & & 100 & 99.9075 & & & & 0.096 & $0.0000 E+00$ \\
\hline Aluminum & 0.033872 & & & 26.98154 & 1.7388E-03 & 0.913919 & 1 & 1.7388E-03 \\
\hline Copper & 0 & & & 63.546 & $0.0000 E+00$ & 0 & 1 & \\
\hline & & 63 & 62.9296 & & & & 0.692 & $0.0000 E+00$ \\
\hline & & 65 & 64.9278 & & & & 0.308 & $0.0000 \mathrm{E}+00$ \\
\hline Nitrogen & 0 & & & 14.0067 & $0.0000 E+00$ & 0 & 1 & $0.0000 E+00$ \\
\hline Iron & 0.014 & & & 55.847 & $3.4722 \mathrm{E}-04$ & 0.781858 & 0.997 & \\
\hline & & 54 & 53.9396 & 0.059 & & & 0.058 & 2.0139E-05 \\
\hline & & 56 & 55.9349 & 0.9172 & & & 0.939 & $3.2604 \mathrm{E}-04$ \\
\hline Hydrogen & 0.01 & & & 1.0079 & 1.3742E-02 & & 1 & 1.3742E-02 \\
\hline Oxygen & 0.529107 & & & 15.9994 & 4.5805E-02 & & 1 & 4.5805E-02 \\
\hline Sodium & 0.016 & & & 22.98977 & 9.6396E-04 & & 1 & 9.6396E-04 \\
\hline Magnesium & 0.002 & & & 24.305 & 1.1397E-04 & & 1 & \\
\hline & & 24 & 23.985 & & & & 0.7899 & 9.0028E-05 \\
\hline & & 25 & 24.9858 & & & & 0.1 & 1.1397E-05 \\
\hline & & 26 & 25.98259 & & & & 0.1101 & 1.2549E-05 \\
\hline Potassium & 0.013 & & & 39.0983 & 4.6053E-04 & & 0.999883 & \\
\hline & & 39 & 38.9637 & & & & 0.067302 & 3.0995E-05 \\
\hline & & 41 & 40.9618 & & & & 0.932581 & 4.2948E-04 \\
\hline Calcium & 0.044 & & & 40.078 & 1.5206E-03 & & 1 & 1.5206E-03 \\
\hline & & 40 & 39.9626 & & & & 0.96941 & $1.4741 \mathrm{E}-03$ \\
\hline & & 42 & 41.9586 & & & & 0.00647 & $9.8384 \mathrm{E}-06$ \\
\hline & & 43 & 42.9588 & & & & 0.00135 & $2.0528 \mathrm{E}-06$ \\
\hline & & 44 & 43.9555 & & & & 0.02086 & $3.1720 \mathrm{E}-05$ \\
\hline & & 46 & 45.9537 & & & & 0.00004 & 6.0824E-08 \\
\hline & & $\underline{48}$ & 47.9525 & & & & 0.00187 & 2.8435E-06 \\
\hline
\end{tabular}

Total $\quad 1.009$

Density $(\mathrm{g} / \mathrm{cc}) \quad 2.30$ 
A-4. Simplified (RZ) Layout of Upper Reflector Used for Computing Structural Volumes

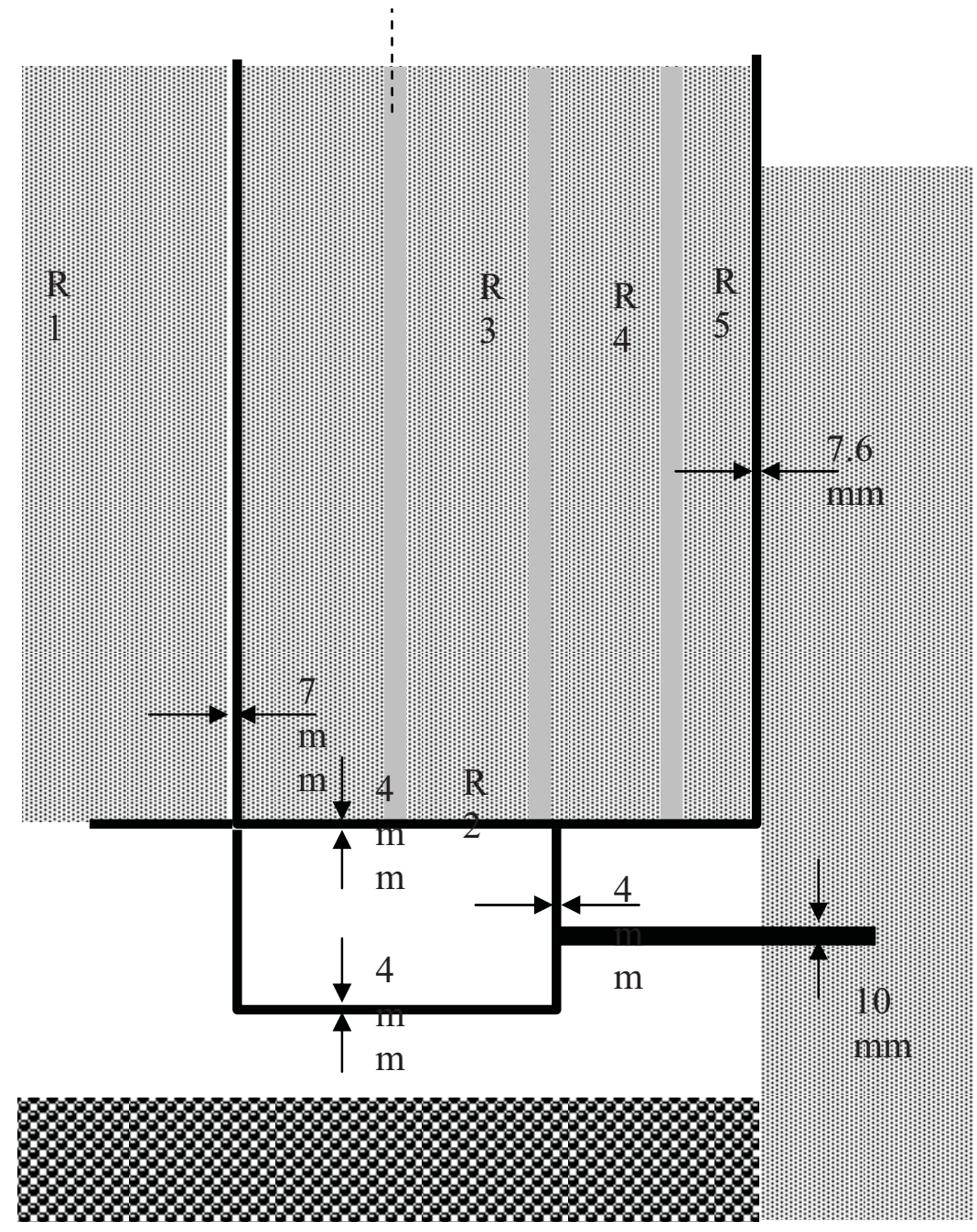




\section{A-5. 1-D Geometric Models Used for SCAMP}

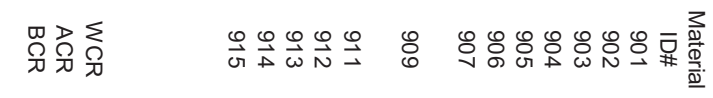

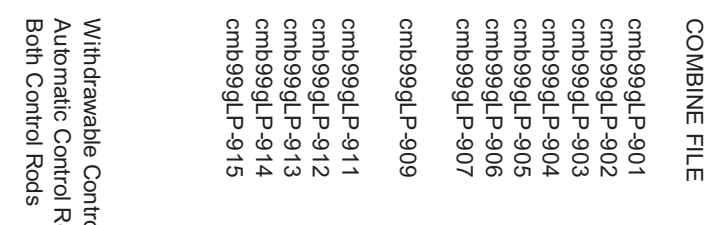

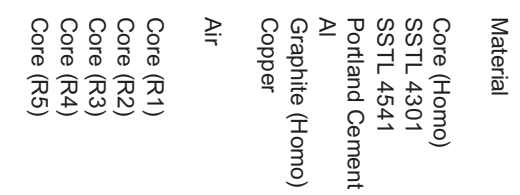

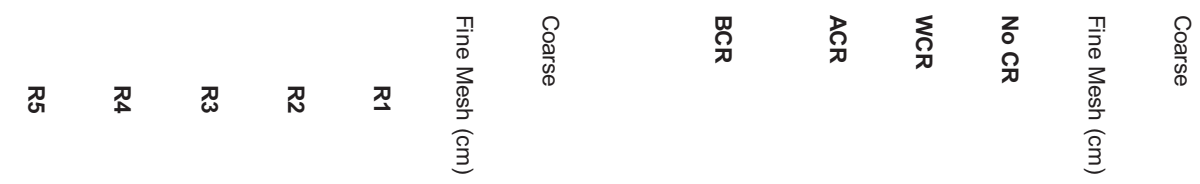

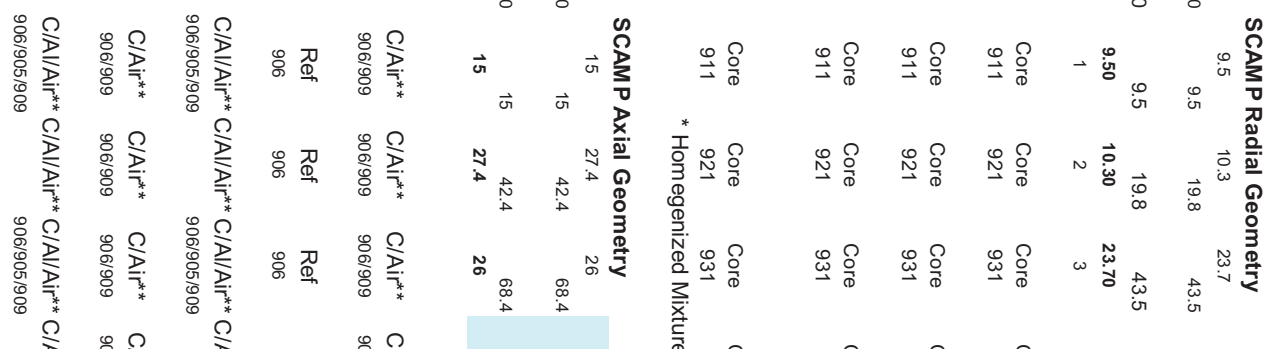

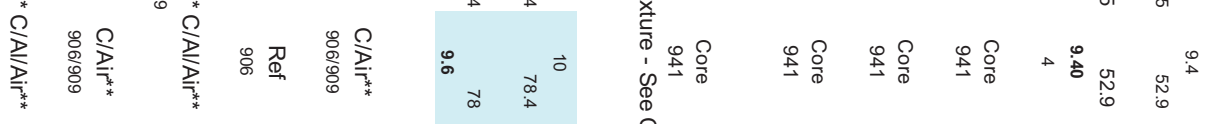

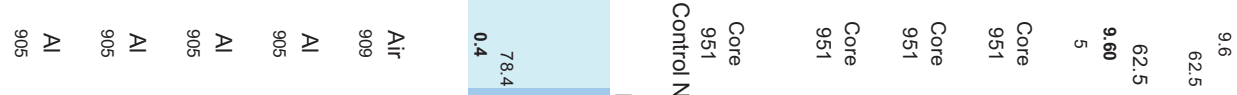

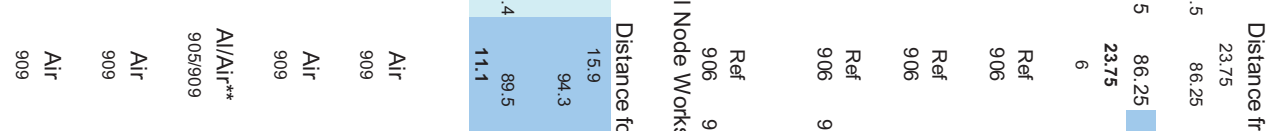

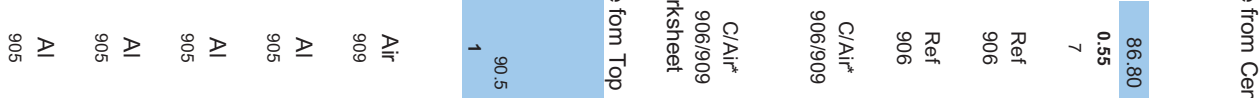

$$
\begin{aligned}
& \text { \& }
\end{aligned}
$$

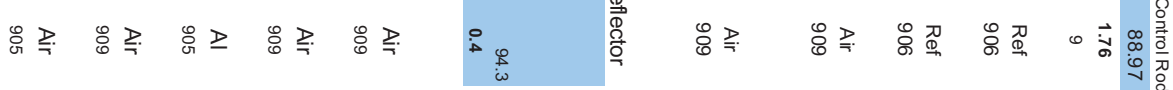

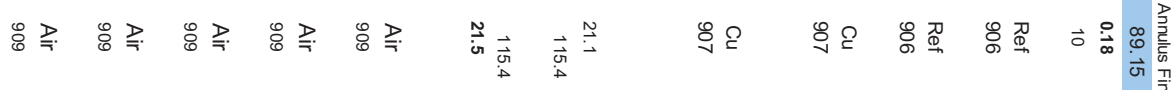

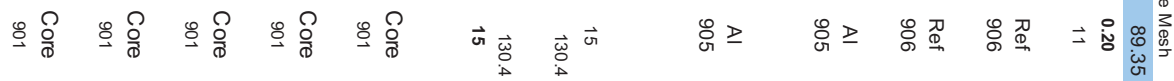

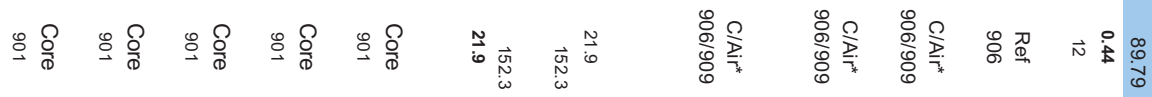

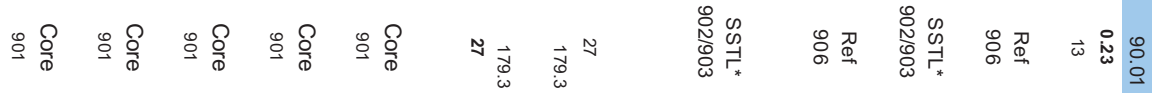




\section{A-6. Detailed RZ Geometry of Proteus Core 4.2}

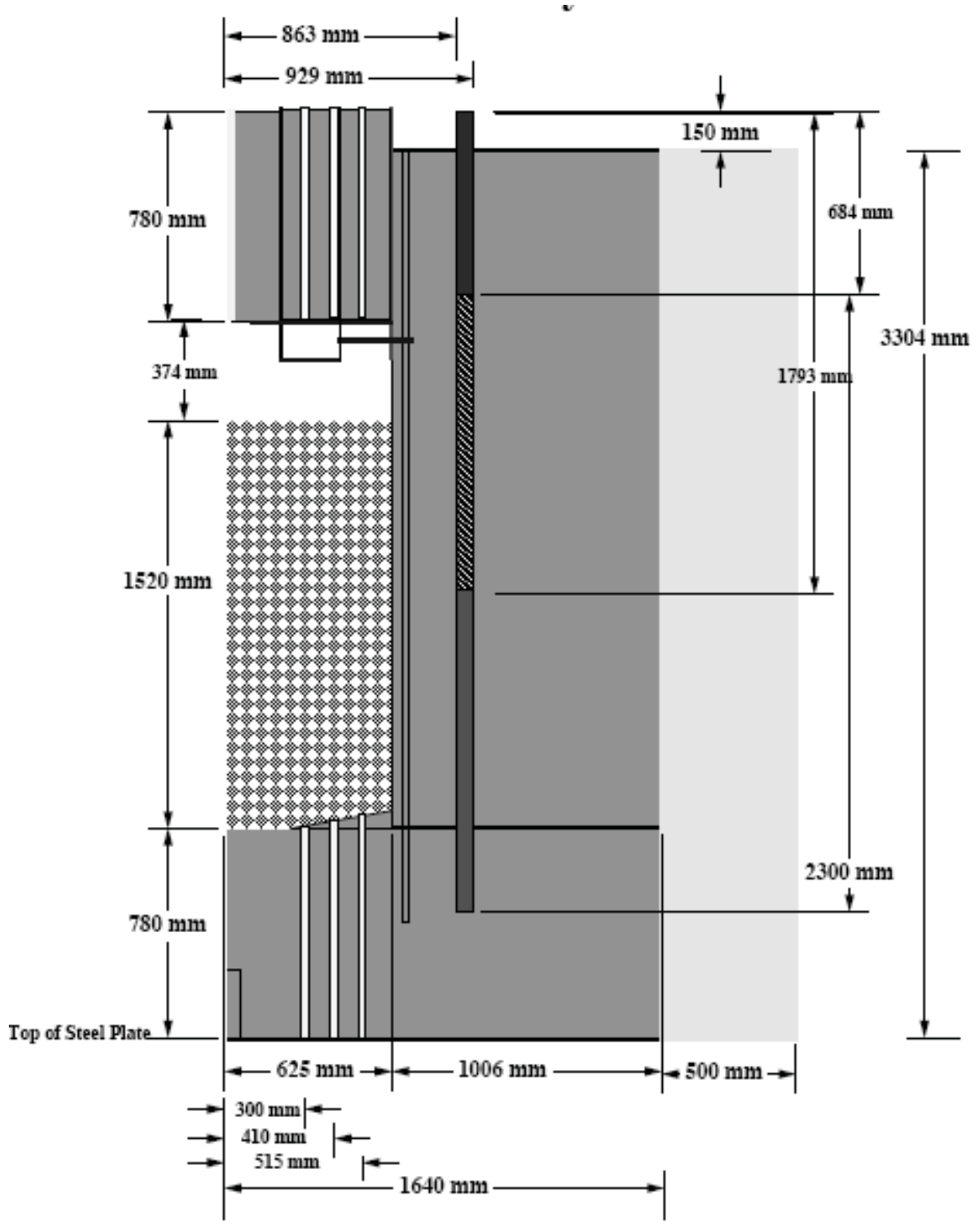




\section{A-7. Material Assignment in the RZ Model}

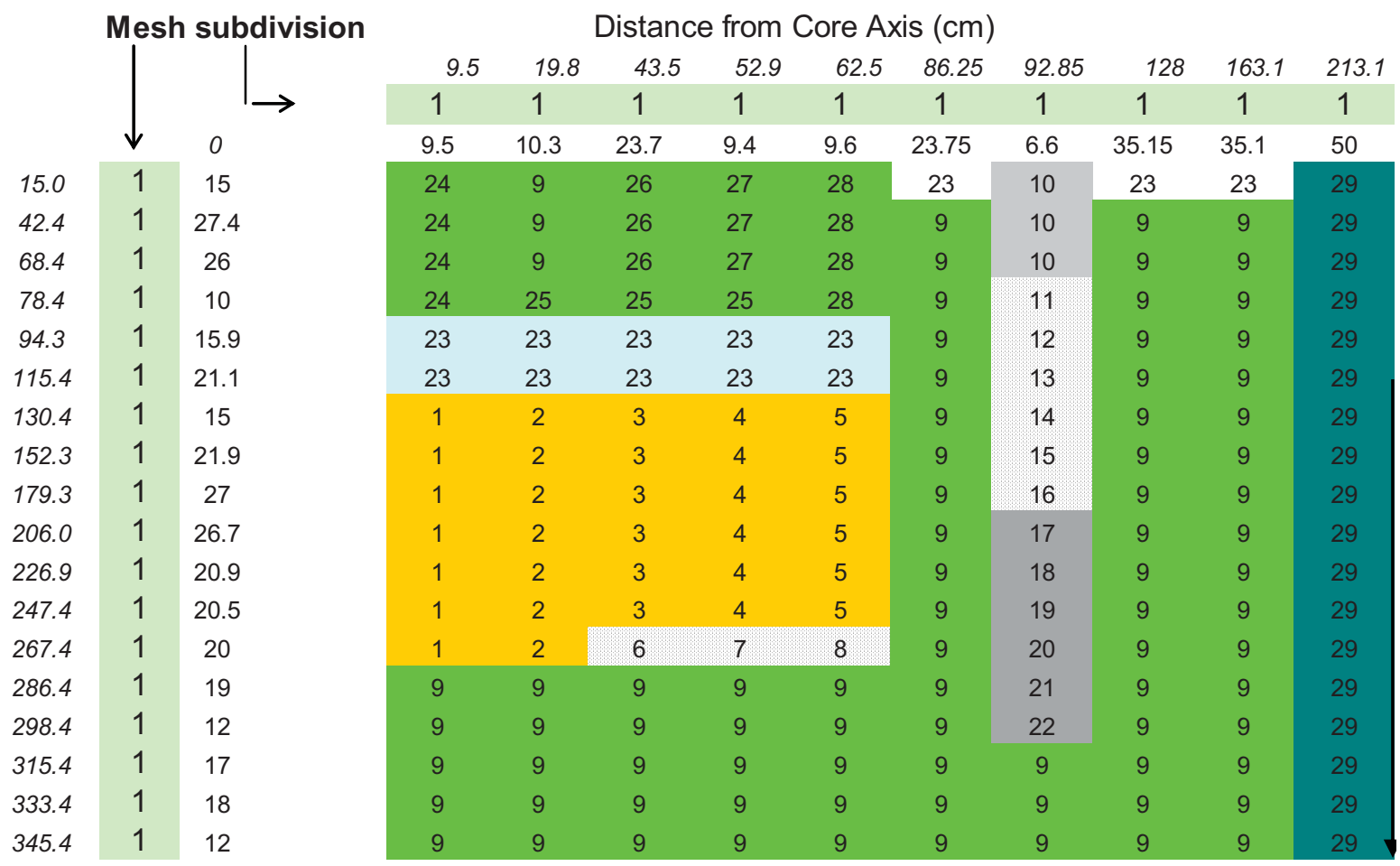

$\begin{array}{cl}\text { COMP \# } & \text { COMPOSITIONS } \\ \mathbf{1} & \text { Core Radial Zone 1 } \\ \mathbf{2} & \text { Core Radial Zone 2 } \\ \mathbf{3} & \text { Core Radial Zone 3 } \\ \mathbf{4} & \text { Core Radial Zone } 4 \\ \mathbf{5} & \text { Core Radial Zone 5 } \\ \mathbf{6} & \text { Core/Ref Wedge } 4 \\ \mathbf{7} & \text { Core/Ref Wedge 5 } \\ \mathbf{8} & \text { Core/Ref Wedge 6 } \\ \mathbf{9} & \text { Pure Graphite Reflector } \\ \mathbf{1 0} & \text { WCR } \\ \mathbf{1 1} & \text { BCR } \\ \mathbf{1 2} & \text { BCR } \\ \mathbf{1 3} & \text { BCR } \\ \mathbf{1 4} & \text { BCR } \\ \mathbf{1 5} & \text { BCR } \\ \mathbf{1 6} & \text { BCR } \\ \mathbf{1 7} & \text { ACR } \\ \mathbf{1 8} & \text { ACR } \\ \mathbf{1 9} & \text { ACR } \\ \mathbf{2 0} & \text { ACR } \\ \mathbf{2 1} & \text { ACR } \\ \mathbf{2 2} & \text { ACR } \\ \mathbf{2 3} & \text { Void } \\ \mathbf{2 4} & \text { Al/C/Air Top Reflector } 1 \\ \mathbf{2 5} & \text { Al/C/Air Top Reflector } 2 \\ \mathbf{2 6} & \text { Al/C/Air Top Reflector } 3 \\ \mathbf{2 7} & \text { Al/C/Air Top Reflector } 4 \\ \mathbf{2 8} & \text { Al/C/Air Top Reflector } 5 \\ \mathbf{2 9} & \text { Concrete } \\ & \\ & \end{array}$

